\title{
Improvement of Summer Precipitation Simulation by Correcting Biases of Spring Soil Moisture in the Seasonal Frozen-Thawing Zone over the Northern Hemisphere
}

\section{Kechen Li}

Lanzhou University

Feimin Zhang

Lanzhou University

Kai Yang

Lanzhou University

Jiali Shen

Lanzhou University

Chenghai Wang ( $\nabla$ wch@lzu.edu.cn )

College of Atmospheric Sciences, Lanzhou University https://orcid.org/0000-0002-7122-7160

\section{Research Article}

Keywords: soil moisture, seasonal freeze-thaw region, indirect soil nudging, precipitation simulation

Posted Date: May 10th, 2021

DOl: https://doi.org/10.21203/rs.3.rs-474839/v1

License: (c) (i) This work is licensed under a Creative Commons Attribution 4.0 International License.

Read Full License

Version of Record: A version of this preprint was published at Climate Dynamics on November 1st, 2021. See the published version at https://doi.org/10.1007/s00382-021-06032-z. 


\section{Abstract}

Soil moisture (SM) plays an important role in the climate system, and the effects of SM anomalies on climate can persist from month to season. The seasonal frozen-thawing zone (SFTZ) is accompanied by apparently inter-annual SM variability, and it is a key region of land-atmosphere interactions in the Northern Hemisphere (NH). In this study, by assimilating spring SM in the SFTZ through indirect soil nudging (ISN) in the Weather Research and Forecasting (WRF) model, the impacts of correcting spring SM biases in the SFTZ on the subsequent summer precipitation simulations in the $\mathrm{NH}$ were investigated. The results indicated that correcting spring SM biases in the SFTZ significantly improves the subsequent summer precipitation simulations in the NH. Correcting spring SM biases in the SFTZ significantly adjusts energy and moisture evolution on the land surface from spring to summer. Specifically, the correction of SM biases by assimilating SM in SFTZ in the spring can clearly reduce the biases of sensible heat flux (SH) and latent heat flux ( $\mathrm{LH})$ in the summer. This affects land-atmosphere interactions over $\mathrm{NH}$, leading to correcting the negative biases of the geopotential height in the middle troposphere in June and July, as well as larger biases of water vapor transport and its divergence during the summer. Overall, it is evident that spring SM in the SFTZ can serve as an effective signal for predicting summer precipitation in the $\mathrm{NH}$.

\section{Introduction}

Land-atmosphere interactions play a critical role in climate variation. Soil moisture (SM) variability changes surface albedo and soil heat capacity, which affect the surface sensible heat flux (SH), latent heat flux (LH), and radiation budget (e.g., Amenu et al., 2005; Song et al., 2009). Additionally, SM variability regulates precipitation and evapotranspiration by altering the surface water balance (e.g., Bounoua and Krishnamurti 1993; Wu et al., 2002). SM anomalies contribute to climate variations on the sub-seasonal to seasonal scale owing to its long-lasting effects (e.g., Koster et al., 2004; Li et al., 2016; Seneviratne et al., 2006a, 2006b, 2013; Wang et al.,2003,2010;Yang et al., 2019a, 2019b). In the midlatitudes of the Northern Hemisphere (NH), effect of SM on climate is more distinct than it is in the low or high latitudes, in terms of increased distance from the ocean (Yeh et al., 1984; Seneviratne et al., 2006a, $2006 \mathrm{~b}, 2010)$. This means that the variability of atmospheric circulation in the mid-latitudes of the $\mathrm{NH}$ is mainly affected by land-atmosphere interactions besides thermodynamic force from the low and high latitudes. Additionally, statistical analysis suggests that the seasonal frozen-thawing zone (SFTZ) in the $\mathrm{NH}$ shows the largest inter-annual variability in spring SM (Yang et al., 2016). This suggests that the characteristics and patterns of atmospheric circulation will be changed by the significant SM anomalies induced by freeze-thaw processes in soil when air passes through the mid-latitude SFTZ during the spring (Yang et al., 2016; Yang and Wang, 2019a, Jiang and Wang, 2020). Therefore, SM variations in the SFTZ combined with freeze-thaw processes in the soil are particularly important in the $\mathrm{NH}$ during the spring.

Studies have indicated that perturbing the initialization of SM significantly influences precipitation simulations. SM-sensitive experiments demonstrate that SM anomalies affect precipitation on time 
scales from days to months and spatial scales from regional to global (e.g., Walker and Rowntre, 1977; Shukla and Mintz, 1982; Douville et al., 2001; Douville, 2002). Studies have further suggested that more realistic SM initialization and evolution in the models contribute to the preciseness of precipitation predictions on the sub-seasonal and seasonal time scales (e.g., Koster et al., 2004, 2010; Vitart et al., 2008; Douville, 2009; Prodhomme et al., 2016; Wang and Cui 2018). Yang et al. (2016) perturbed the initial SM in a series of sensitivity experiments and provides evidence that the spring SM anomaly in the SFTZ could lead to subsequent summer precipitation anomalies in the $\mathrm{NH}$. However, their study did not focus on the impact of SM bias corrections in the SFTZ on the NH climate simulation. Additionally, largescale and non-local impacts from spring SM in the SFTZ on precipitation in the $\mathrm{NH}$ remain unclear because most studies focus on local SM-precipitation coupling (e.g., Joussaume et al., 1984; Koster et al., 1986; Taylor et al., 2007; Alfieri et al., 2008; Santanello et al., 2009). Therefore, it is urgent to investigate the impacts of correcting spring SM biases in the SFTZ on the subsequent climate simulation.

SM biases are pervasive in current databases such as reanalysis databases (Ni-Meister et al.,2005; Yang et al., 2016), which cause initial conditions and boundary conditions (ICBCs) to contain SM biases. How to improve the ICBCs in SM is a key issue in climate simulations, and the accuracy of SM in land surface models can be improved by assimilating observed SM data. The problem with assimilating SM data in the root zone arises from the lack of in situ SM observations globally, especially in the SFTZ. Although satellite-based SM observations have become increasingly available in recent years, the observed depth of most of them is under $10 \mathrm{~cm}$, and the data quality is significantly affected by differences in soil texture, landscape, vegetation coverage, and precipitation (Gao et al., 2006; Kerr et al., 2012). Furthermore, numerical models have been used to improve the spatiotemporal resolution of SM data, but the SM simulation performance was not consistent between different models owing to flawed model parameters (Guo and Dimeyer, 2006; Dirmeyer, 2011). In the Pleim-Xiu land surface model (PXLSM), Pleim and Xiu (2003) developed the indirect soil nudging (ISN) assimilation scheme, which used differences in 2-m air temperature $\left(T_{2 m}\right)$ and 2-m relative humidity $\left(R H_{2 m}\right)$ between models and observations to dynamically adjust the SM. Wang and Cui (2018) provided evidence that SM assimilation using ISN improved shortterm climate predictions in China. Thus, ISN is a reliable method for SM assimilation in the SFTZ. Considering the evident SM biases in SFTZ (Yang et al., 2016), the contribution of correcting spring SM in the SFTZ to summer precipitation predictions remains unclear. On this basis, this study aims to evaluate the summer precipitation simulation through correcting spring SM in the SFTZ and to explain the possible mechanisms.

Three main issues will be addressed: (1) Can spring SM biases in the SFTZ be corrected by nudging scheme? (2) Can summer precipitation simulations in the $\mathrm{NH}$ be improved by correcting spring SM biases over the SFTZ? (3) What are the possible mechanisms linked to the improvement in summer precipitation simulations by correcting spring SM biases over the SFTZ? Answering these issues will improve our knowledge on the large-scale and non-local effects of SM in the SFTZ and SM initialization in regions without in situ SM observations on precipitation in the $\mathrm{NH}$. 
The remainder of this study is organized as follows: Section 2 provides a brief description of the model, data, and experiment design. Section 3 shows the corrected spring SM simulation biases after assimilating spring SM in the SFTZ. Section 4 shows the validation of summer precipitation simulation performance after correcting spring SM biases. Section 5 shows the changes in land surface elements by correcting spring SM biases in the SFTZ. Section 6 discusses the possible mechanisms behind the improvement of precipitation simulation in the $\mathrm{NH}$. Section 7 provides conclusions and overall findings of the study.

\section{Data And Methods}

\subsection{Model and data}

The Advanced Research version of the Weather Research and Forecasting Model (WRF-ARW, version 3.9.1) was used in this study. The ICBCs were provided by National Centers for Environmental Prediction (NCEP) final analysis data (FNL) with spatial and temporal resolutions of $1^{\circ} i^{\circ}$ and $6 \mathrm{~h}$, respectively. $T_{2 m}$ and $R H_{2 m}$ were calculated and interpolated through objective analysis using global surface observational weather data (spatial resolution: $0.5^{\circ}$ i $0.5^{\circ}$; temporal resolution: $6 \mathrm{~h}$ ) with automatic data processing provided by the NCEP. SM, SH, and LH data were obtained from ERA-Interim (spatial resolution: $0.5^{\circ} 10.5^{\circ}$; temporal resolution: $6 \mathrm{~h}$ ), ERA5 (spatial resolution: $0.5^{\circ}$ I $0.5^{\circ}$; temporal resolution: $1 \mathrm{~h}$ ), and the Noah land surface model from the Global Land Data Assimilation System (GLDAS) version 2.1 (spatial resolution: $0.25^{\circ}$ I $0.25^{\circ}$; temporal resolution: $3 \mathrm{~h}$ ) was used for simulation verification (Dee et al., 2011; Hersbach and Dee, 2016; Chen et al., 1996; Koren et al., 1999). The daily global precipitation analysis (spatial resolution: $0.5^{\circ} \mathrm{I}_{0.5^{\circ}}$ ) from the Climate Prediction Center (CPC; Chen et al., 2008) was used to evaluate the WRF model precipitation simulation performance. Additionally, The ERA5 dataset was used to compare the simulation results of geopotential height at $500 \mathrm{hPa}$ and water vapor flux with its divergence at $850 \mathrm{hPa}$.

The simulation performance was quantitatively assessed using root-mean-square error (RMSE). The RMSE is defined as follows:

$$
R M S E=\sqrt{\frac{1}{n} \sum_{i=1}^{n}\left(F_{i}-O_{i}\right)^{2}}
$$

where $F$ and $O$ are the simulation and verifying observation with the same physical units and $\mathrm{N}$ is the total grid points in the validation domain.

\subsection{Definition of SFTZ}

The SFTZ is a region that is surrounded by $0{ }^{\circ} \mathrm{C}$ isotherms in January and by an annual climatological mean of $0{ }^{\circ} \mathrm{C}$ isotherms (Zhang et al., 2003, Jiang and Wang, 2020). The SFTZ in this study is shown in 
Figure 1, circled with a blue line. Figure 1 further shows that the maximum standard deviation of spring SM at soil depth $0-1 \mathrm{~m}$ from ERA5 occurs primarily over the SFTZ in the mid-latitudes of the $\mathrm{NH}$, indicating that the largest inter-annual variability of SM is in the SFTZ (Yang et al., 2016).

\subsection{Experimental design}

To exclude the impacts from sea surface temperature anomalies, a 7-month simulation (February to August 2004) based on the WRF model (version 3.9.1) was conducted because neither an El Niño nor a La Niña event occurred in 2004. Figure 1 shows the simulation domain, which covers the entire $\mathrm{NH}$ with 360 í 360 grid points. The selected physical parameterization schemes for the simulation were the KainFritsch cumulus scheme (Kain, 2004), the Rapid Radiative Transfer Model for General Circulation Models (RRTMG, lacono et al., 2008) for the longwave and shortwave radiation schemes, the ACM2 (Pleim) planetary boundary layer scheme (Pleim, 2007), the Pleim-Xiu surface layer scheme (Pleim, 2006), the WRF Double-Moment 6-Class cloud microphysics scheme (Lim and Hong, 2010), and the Pleim-Xiu land surface scheme (Pleim and Xiu, 2003). The Pleim-Xiu land surface scheme contains a surface soil layer $(0-1 \mathrm{~cm})$ and a deep soil layer $(1-100 \mathrm{~cm})$.

Two experiments were designed to investigate the effects on subsequent summer precipitation in the $\mathrm{NH}$ from correcting spring SM biases over the SFTZ: the control experiment (CTL), which used the Pleim-Xiu land surface scheme (Pleim and Xiu, 2003) without assimilating any observations, and the assimilation experiment (ISN), which used the ISN method in the Pleim-Xiu land surface scheme to assimilate spring SM in the SFTZ. In the ISN experiment, we updated SM tendencies every $3 \mathrm{~h}$ by comparing the current forecast values of $T_{2 m}$ and $R H_{2 m}$ with the observed values interpolated from periodic objective analyses. During the night, deep temperature nudging was used to complement SM nudging according to the model bias in $T_{2 m}$ because surface forcing is weak at that time (Pleim and Gilliam, 2009).

\section{Improvement Of The Sm Simulation In The Sftz By Assimilating Spring Sm}

To investigate the effectiveness of spring SM assimilation in the SFTZ on correcting SM simulation biases, the correlation coefficients of SM between two experiment (CTL and ISN) simulations and three reanalysis datasets (ERA-Interim, ERA5, and GLDAS2.1 Noah) are shown in Figure 2. In the CTL experiment, SM shows no significant correlation with ERA-Interim, ERA5, or GLDAS2.1 Noah across the mid-latitudes (Figures $2 a-c$ ). This suggests that spring SM variations in the SFTZ are not captured in the CTL experiment, which implies that the spring freeze-thaw processes are poorly represented. After assimilating spring SM in the SFTZ, significant correlations reveal that SM in the ISN experiment is consistent with the three reanalysis data in the SFTZ (Figures $2 d-f$ ). Additionally, it should be noted that there are high correlation coefficients outside of the SFTZ in the CTL and ISN experiments, which means that the model is unable to accurately simulate the evolution of SM in the SFTZ (Figures 2a-f). 
To further investigate the effects of assimilating spring SM in the SFTZ on SM simulations, the differences in SM between two experiments (CTL and ISN) and three reanalysis data (ERA-Interim, ERA5, and GLDAS2.1 Noah) were calculated (Figure 3). Previous studies (e.g., Douville et al., 2001; Yang et al., 2016) suggested that SM impacts precipitation more than oceanic effects in mid-latitudes, and to analyze the performance of SM assimilation, SM variation in the North America and Eurasia at the 30$60^{\circ} \mathrm{N}$ was selected to represent SM variation in the SFTZ because the SFTZ is essentially located in this region, though the boundary of the SFTZ shows inter-annual variations. It was evident that there are wet biases of SM simulation in the two experiments in the SFTZ and in the $\mathrm{NH}$ (Figures 3a-c). The wet biases of SM in the CTL experiment have no consistent increasing or decreasing trend in the North American SFTZ (Figure 3a), an increasing trend from March to June in the Eurasian SFTZ (Figure 3b), and an increasing trend overall in the $\mathrm{NH}$ (Figure 3c). After assimilating spring SM in the SFTZ, wet biases of SM in the SFTZ had a clearly descending trend from March to August in the ISN experiment (Figures 3a, b). In the NH (Figure 3c), wet biases of SM in the ISN experiment decreased from March to June and increased from June to August. This suggests that assimilating spring SM in the SFTZ cannot suppress the overall increasing wet biases of SM in the NH from June to August. In addition, wet biases of SM in the ISN experiment are smaller than those in the CTL experiment from May to August. As shown in Figure 3, there are large increases of SM wet biases from March to April in the CTL experiment, which means that SM variation from March to April cannot be well simulated. This may be because soil is still frozen. In the CTL experiment, it was found that SM wet biases in the SFTZ only had a slight variation from June to August when compared with the variation from March to June (Figures 3a, b), and wet SM biases in the $\mathrm{NH}$ maintain a consistent increasing trend from March to August (Figure 3c). This suggests that the wet biases of SM in the SFTZ are primarily induced in the spring, and the wet biases of SM in May influence the degree of wet biases of SM in the summer in the SFTZ, whereas wet biases of SM outside the SFTZ still increase in the summer. This reflects the importance of the assimilation of spring $\mathrm{SM}$ in the SFTZ on the subsequent summer climate prediction. Additionally, it is found that the wet biases of SM decrease the most from April to May in the ISN experiment (Figures 3a-c), which suggests that the assimilation of spring SM in the SFTZ may be more suitable from April to May than in March.

As the wet biases of SM in the SFTZ in May approximately reflect the wet biases of SM in the summer and influence the subsequent climate in June and July due to SM memory, the biases of SM in May are calculated in Figure 4. The main biases of SM in the CTL experiment in May are more concentrated in the SFTZ when compared with the three reanalysis data (Figures $4 a-c$ ). Results in Figures $4 d-f$ suggest that assimilating spring SM in the SFTZ decreases the wet biases of SM in May in the ISN experiment.

Overall, the simulation biases of SM in the SFTZ are clearly reduced in the ISN experiment compared to the CTL experiment. In the next section, the effects of the correcting SM simulation biases in the SFTZ on subsequent summer precipitation simulations over the $\mathrm{NH}$ will be analyzed.

\section{Effects Of Correcting Spring Sm Simulation Biases In The Sftz On The Subsequent Summer Precipitation Simulation In The Nh}


To evaluate the simulation performance of summer precipitation after correcting spring SM simulation biases in the SFTZ, the RMSE of land precipitation was calculated based on CPC precipitation data, while the RMSEs of three latitude bands of precipitation were calculated to assess if correcting spring SM biases in the SFTZ improved the subsequent summer precipitation simulation in the $\mathrm{NH}$ (Figure 5).

In the low and middle latitudes (Figures 5a, b), RMSEs of summer precipitation in June, July, and the overall summer simulated by ISN are lower than that in CTL, whereas a higher RMSE is found in August in the ISN experiment. This indicates that correcting spring SM biases in the SFTZ improves land precipitation simulations in June, July, and the overall summer in the lower and middle latitudes. In the high latitudes (Figure 5c), assimilating spring SM in the SFTZ seems to cause a poor simulation of land precipitation in June, August, and the overall summer. The simulation performance of land precipitation in the $\mathrm{NH}$ (Figure 5d) is similar to the results in the low and middle latitudes (Figures 5a, b). Therefore, correcting spring SM biases in the SFTZ can influence summer precipitation prediction in the $\mathrm{NH}$. In addition, the improvement of land precipitation simulation in summer in the $\mathrm{NH}$ is located in the low and middle latitudes in June and July.

To investigate the reasons for the differences in simulation performance of land precipitation in the two experiments, the ratio of precipitation biases of the CTL experiment and the ISN experiment is calculated based on CPC precipitation data (Figure 6). The ratio in Figures 6a-d was calculated by dividing precipitation biases of the CTL experiment by precipitation biases of the ISN experiment, where absolute values of a ratio greater than 1.0 indicate that the ISN experiment has a better precipitation simulation. The ratios in Figures $6 \mathrm{e}-\mathrm{h}$ are the multiplicative inverse of results in Figures $6 \mathrm{a}-\mathrm{d}$ which means that the CTL experiment has a better precipitation simulation with absolute values of a ratio greater than 1.0. There are basically wet biases of precipitation in the CTL and ISN experiments (Figures not shown). Therefore, the results shown in Figures $6 a-c$ suggest that correcting spring SM biases in the SFTZ improved the summer precipitation simulation by decreasing the wet biases of precipitation. However, the results in Figures $6 \mathrm{e}-\mathrm{h}$ show that correcting SM biases also cause a worse precipitation simulation by increasing the wet biases of precipitation. Furthermore, the ISN experiment has apparent wet biases in Northeast Asia in August, which explains why the RMSE of the ISN experiment is larger in the $60-90^{\circ} \mathrm{N}$ in August than that in the CTL experiment in Figure 5c.

Correcting wet biases in spring SM in the SFTZ can significantly improve the land precipitation simulation in June and July in the low and middle latitudes. Precipitation simulation in August is not improved, especially in the high latitudes. Overall, the summer precipitation simulation is improved in the $\mathrm{NH}$.

\section{Improvement Of Elements In Land-atmosphere Interaction After Correcting Sm Biases In The Sftz}

Section 4 provided evidence that correcting spring SM biases in the SFTZ can improve the summer precipitation simulation. Because SM is important for regulating land-atmosphere interactions, the 
differences in the precipitation simulations of the two experiments should be related to the landatmosphere interactions affected by SM changes. Thus, the next question that needs be further investigated is: what changes in quantities of land-atmosphere interactions occur after assimilation?

To investigate the surface heat changes caused by correcting spring SM biases in the SFTZ, the RMSE of $\mathrm{LH}$ and $\mathrm{SH}$ at $30-60^{\circ} \mathrm{N}$ of the two experiments (CTL and ISN) is compared with the three reanalysis data (ERA-Interim, ERA5, and GLDAS2.1 Noah), as shown in Figure 7. Similar to the comparison of SM variation (Figure 3), $\mathrm{LH}$ and $\mathrm{SH}$ at $30-60^{\circ} \mathrm{N}$ are selected. Results show that ISN experiment has a worse LH simulation from March to June compared with the three reanalysis data, but the ISN experiment has a better LH simulation from July to August compared with ERA-Interim, and ERA5 and a worse LH simulation from July to August compared with GLDAS2.1 Noah (Figures 7a-c). Overall, the ISN experiment has a worse LH simulation in the spring and a better LH simulation in the summer compared with the CTL experiment. The ISN experiment has a better $\mathrm{SH}$ simulation from April to July, but it is difficult to judge which experiment has a better SH simulation in March and August when compared with the three reanalysis data (Figures $7 d-f$ ). Overall, the ISN experiment has a better SH simulation in the spring and summer. These results indicate that correcting spring SM biases in the SFTZ improve the SH simulation in the SFTZ in the spring and summer, but the improvement of $\mathrm{LH}$ simulation in the spring is marginal.

To investigate why correcting spring SM biases in the SFTZ changes the LH and SH simulations in the SFTZ, the simulation biases of spring and summer LH in the two experiments (CTL and ISN) were compared with the three reanalysis data (ERA-Interim, ERA5, and GLDAS2.1 Noah), as shown in Figures 811. It can be seen that the spatial pattern of biases of SH and LH outside of the SFTZ is similar between the two experiments. In Figures 8, it is evident that both experiments have warm biases of LH in the SFTZ, but the CTL experiment has smaller warm biases of LH than has the ISN experiment in the SFTZ in the spring. In summer, both warm and cold biases of LH can be found in the SFTZ in the two experiments (Figures 9). It was evident that LH biases of the CTL experiment increased from spring to summer, which led to a larger LH RMSE in the CTL experiment than that in the ISN experiment in the summer (Figures 7ac).

In the SH simulations, the CTL experiment has cold SH biases in spring in the SFTZ while the ISN experiment had smaller SH biases in spring in the SFTZ (Figure 10). Consequently, SH biases in the SFTZ in the CTL experiment clearly increased in the summer (Figures 11a-c), whereas the ISN experiment only has warm SH biases in the summer around central Asia (Figures $11 \mathrm{~d}-\mathrm{f}$ ). These results explain the smaller RMSE of SH in the SFTZ in the ISN experiment from spring to summer (Figure $7 d-f$ ).

The spatial pattern of evapotranspiration biases is similar to the LH biases pattern in the two experiments (Figures not shown). After correcting spring SM biases in the SFTZ, the simulation of evapotranspiration was adjusted, which subsequently influenced the simulation of $\mathrm{LH}$ and $\mathrm{SH}$. Overall, correcting spring SM biases in the SFTZ improved the simulation of summer LH and spring and summer SH in the SFTZ. Specifically, it suppressed the increase of LH biases in the SFTZ in summer, though assimilating spring 
SM in the SFTZ caused the worse simulation of evaporation in spring. Additionally, correcting spring SM biases in the SFTZ also continuously corrects the cold SH biases from spring to summer. Therefore, correcting spring SM biases in the SFTZ indeed improved the land surface energy conditions in the SFTZ, which are beneficial to the summer precipitation simulation in the $\mathrm{NH}$.

\section{Possible Mechanisms For The Contribution Of Correcting Spring Sm Biases In The Sftz To The Subsequent Summer Precipitation}

As demonstrated by Yang et al. (2016), energy anomalies on the land surface of the SFTZ can induce anomalous circulations, which subsequently influence the summer precipitation simulation.

To assess the atmosphere circulation simulation, RMSEs of the $500-\mathrm{hPa}$ geopotential height are calculated in the spring and summer from March to August (Figure 12). There were smaller RMSEs of the 500-hPa geopotential height in the low latitudes (Figure 12a) than in the middle and high latitudes (Figures 12b, c). The biases of the ISN experiment are similar to those in the CTL experiment because the atmospheric circulations in the low latitudes are dominated by tropical sea surface temperature. In the mid-latitudes, the ISN experiment has a better simulation of the 500-hPa geopotential height than the CTL experiment, except for that in April (Figure 12b). In the high latitudes, the ISN experiment has a better simulation of the 500-hPa geopotential height than that in the CTL experiment, except for that in March and August (Figure 12c). Similarly, in the $\mathrm{NH}$, the ISN experiment has a better simulation of the 500-hPa geopotential height than has the CTL experiment, except for that in March and August (Figure 12d). The worse simulations of $500-\mathrm{hPa}$ geopotential height in the $\mathrm{NH}$ in March and August are primarily due to the worse simulation in the high latitudes. The simulation of the $500-\mathrm{hPa}$ geopotential height is clearly improved in the middle and high latitudes in June and July (Figures 12b, c), which may be responsible for the improvement of the precipitation simulation in the low and middle latitudes in June and July.

To further investigate the reasons for the improvement of the 500-hPa geopotential height, simulation biases of the 500-hPa geopotential height in two experiments (CTL and ISN) were compared with that in ERA5, as shown in Figure 13. There are mostly negative biases of the $500-\mathrm{hPa}$ geopotential height in the CTL experiment from June to August, as well as in the whole summer, and the positive biases are mainly located over the ocean (Figures 13a-d). By correcting spring SM biases in the SFTZ, the negative biases of the 500-hPa geopotential height in June and July are reduced, but it also causes an increase of positive biases of the 500-hPa geopotential height (Figures 13e,f), especially in the northern Europe in June. In August, correcting spring SM biases in the SFTZ also leads to an increase in the negative biases of the 500 -hPa geopotential height around northwestern North America (Figure 13g), which explains the larger biases of the $500-\mathrm{hPa}$ geopotential height in the ISN experiment than those in the CTL experiment in the high latitudes (Figure 12c). Overall, assimilating spring SM in the SFTZ improves the 500-hPa geopotential height in the summer in the $\mathrm{NH}$ (Figure 13h).

As the water vapor condition in the lower atmosphere is essential for precipitation, the water vapor flux (WVF) and its divergence at $850 \mathrm{hPa}$ in the summer is compared between two experiments (CTL and ISN) 
and ERA5 (Figure 14). By comparing the biases of the CTL and ISN experiments, it is evident that larger WVF biases of the CTL experiment are found in the NH than those of the ISN experiment. Subsequently, stronger WVF convergence biases are found in the CTL experiment than those in the ISN experiment. These results are responsible for the decrease in wet biases of precipitation shown in Figure 6.

Overall, correcting spring SM biases in the SFTZ improves the subsequent summer precipitation simulation by improving the simulation of large-scale circulation and water vapor conditions in the $\mathrm{NH}$ during the summer.

\section{Conclusions}

This study investigated the impacts of correcting SM biases in the SFTZ over the $\mathrm{NH}$ on the subsequent summer precipitation simulation, using the ISN method in the WRF model. The results suggest that correcting biases of spring SM in the SFTZ can improve the land-atmosphere interaction processes in the spring and summer. In other words, the SFTZ is a crucial region (hot spot) for land-atmosphere interaction.

After correcting spring SM biases in the SFTZ, the simulated variations of SM in the SFTZ from the ISN experiment were significantly correlated with SM from the three reanalysis data (ERA-Interim, ERA5, and GLDAS 2.1 Noah), whereas SM from the CTL experiment showed no significant correlation. Additionally, SM outside of the SFTZ in the two experiments are consistent with SM from the three reanalysis data during the spring, further indicating that the SFTZ is a key region for general circulation anomalies in spring. Assimilating spring SM in the SFTZ also reduces wet biases of SM, causing the SM in the ISN experiment to be closer to the SM in the three reanalysis data in the SFTZ from May to August. Furthermore, wet SM biases are not significantly increased after May in the SFTZ, which suggests that SM biases in May could dominate the magnitude of SM biases in the summer. These results indicate that correcting spring SM biases in the SFTZ can represent the variations of SM during the summer and would improve precipitation simulation in the summer.

The precipitation simulation results show that the ISN experiment has a better performance in the low and middle latitudes in June and July. Wet biases of precipitation are more dominant than dry biases in both the CTL and ISN experiments. Assimilating spring SM in the SFTZ decreases the wet biases of summer precipitation. This explains that correcting the spring SM biases in the SFTZ can reduce the cold biases of $\mathrm{SH}$ in the CTL experiment during spring and summer and it can also decrease the biases of LH in summer. In other words, by assimilating spring SM in the SFTZ, correcting SM can provide a better expression of land surface energy in the SFTZ in the summer.

Correcting spring SM biases in the SFTZ produces a positive effect on precipitation simulations, which is attributed to the improved simulation of the $500-\mathrm{hPa}$ geopotential height in the middle and high latitudes in June and July. However, because persistence effect of SM on atmosphere is approximately 120 days (Yang and Wang, 2019b), the simulation performance becomes worse in August. Further investigation suggests that spring SM improvements in the SFTZ can decrease negative biases of the $500-\mathrm{hPa}$ 
geopotential height in the middle and high latitudes in June and July, while it increases the negative biases in the middle and high latitudes in August. Similarly, correcting spring SM biases in the SFTZ can clearly decrease the WVF and WVF convergence biases. These results demonstrated that spring SM in the SFTZ affects precipitation production and relative general circulation and water vapor conditions throughout the $\mathrm{NH}$ in the summer, especially in June and July.

This study provides the evidence that improving spring SM variability in the SFTZ over the NH can improve the subsequent summer precipitation simulations; the spring SM in the SFTZ can serve as a crucial signal for predicting summer precipitation in the $\mathrm{NH}$.

\section{Declarations}

Acknowledgments: This study is supported by the National Natural Science Foundation of China (NSFC, Nos. 91837205, 41801015, 41805032, and 41975111), and Science Foundation of Gansu province in China (20JR10RA654). We appreciate the European Centre for Medium Range Weather Forecasts (ECMWF) for providing the ERA-Interim reanalysis data (http://apps.ecmwf.int/datasets/data/interim-fullmoda/levtype $=\mathrm{sfc} /$ ) and ERA5 reanalysis data (https://cds.climate.copernicus.eu/cdsapp\#!/dataset/reanalysis-era5-pressure-levels?tab=form), the National Centers for Environmental Prediction (NCEP) for providing the NCEP ADP (Automated Data Processing) global surface observational weather data (https://rda.ucar.edu/datasets/ds461.0/) and final analysis data (FNL, http://rda.ucar.edu/datasets/ds083.2), the National Aeronautics and Space Administration (NASA) Goddard Space Flight Center (GSFC) Hydrological Sciences Laboratory (HSL) and the Goddard Earth Sciences Data and Information Services Center (GES DISC) for providing Global Land Data Assimilation System Version 2 (GLDAS-2) data (https://disc.gsfc.nasa.gov/datasets), and the National Oceanic and Atmospheric Administration (NOAA) Climate Prediction Center for providing daily global precipitation data (https://psl.noaa.gov/data/gridded/data.unified.daily.conus.html).

\section{References}

Alfieri L, Claps P, D'Odorico P, Laio F., Over TM (2008). An analysis of the soil moisture feedback on convective and stratiform precipitation. J.Hydrometeorol. 9 (2), 280-291.

Amenu GG., Kumar P, Liang XZ (2005) Interannual variability of deep-layer hydrologic memory and mechanisms of its influence on surface energy fluxes. J. Clim., 18(23), 5024-5045.

Bounoua L, Krishnamurti TN (1993) Influence of soilmoisture on the Sahelian climate prediction I. Meteor. Atmos. Phys., 52, 183-203.

Dirmeyer PA (2011) History and Review of the Global Soil Wetness Project (GSWP). Journal of Hydrometeorology, 12(5), 729-749. 
Chen F et al (1996), Modeling of land-surface evaporation by four schemes and comparison with FIFE observations. J. Geophys. Res., 101(D3), 7251-7268, doi:10.1029/95JD02165.

Chen M, Xie P et al (2008) CPC Unified Gauge-based Analysis of Global Daily Precipiation. Western Pacific Geophysics Meeting, Cairns, Australia, 29 July - 1 August, 2008.

Dee DP, Uppala SM, Simmons AJ, Berrisford P, Poli P, Kobayashi S, Andrae U, Balmaseda MA, Balsamo G, Bauer DP, Bechtold P (2011) The ERA-Interim reanalysis: configuration and performance of the data assimilation system. Quarterly Journal of the Royal Meteorological Society, 137(656), 553-597.

Douville $H$, Chauvin F, Broqua $H$ (2001) Influence of soil moisture on the Asian and African monsoons. Part I: Mean monsoon and daily precipitation. J. Climate, 14, 2381-2403.

Douville H (2002) Influence of soil moisture on the Asian and African monsoons. Part II: Interannual variability. J. Climate, $15,701-720$.

Douville H (2009) Relative contribution of soil moisture and snow mass to seasonal climate predictability: A pilot study. Climate Dynamics, 34, 797-818. https://doi.org/10.1007/s00382-008-0508-1.

Gao H, Wood EF, Drusch M, Jackson T, Bindlish R (2006) Using TRMM/TMI to retrieve soil moisture over the southern United States from 1988 to 2002. J. Hydrometeorol., 7, 23-38.

Guo Z, Dirmeyer PA (2006) Evaluation of the Second Global Soil Wetness Project soil moisture simulations: 1. Intermodel comparison. Journal of Geophysical Research Atmospheres, 111(D22), 1-14.

Hersbach H, Dee D (2016) ERA-5 reanalysis is in production. ECMWF Newsletter, number 147, 7.

Lim KSS, Hong SY (2010) Development of an effective double-moment cloud microphysics scheme with prognostic cloud condensation nuclei (CCN) for weather and climate models. Mon. Wea. Rev., 138, 15871612.

lacono MJ, Delamere JS et al (2008) Radiative forcing by long-lived greenhouse gases: Calculations with the AER radiative transfer models. J. Geophys. Res., 113, D13103.

Jiang JH, Wang CH (2020) Study on the relationship between seasonal freezing-thawing areas and summer precipitation in the Northern Hemisphere. Journal of Glaciology and Geocryology, 2020, 42(1):53$61,10.7522 /$ j.issn.1000-0240.2020.0015.

Joussaume S, Sadourny R, Jouzel J (1984) A general-circulation model of water isotope cycles in the atmosphere. Nature 311 (5981), 24-29.

Kain JS (2004) The Kain-Fritsch convective parameterization: An update. Journal of Applied Meteorology, 43 (1), 170-181. 
Kerr YH, Waldteufel P, Richaume P, Wigneron JP (2012) The SMOS Soil Moisture Retrieval Algorithm. IEEE Transactions on Geoscience \& Remote Sensing, 50(5), 1384-1403.

Koren V, Schaake J, Mitchell K, Duan QY, Chen F (1999) A parameterization of snowpack and frozen ground intended for NCEP weather and climate models, J. Geophys. Res., 104(D16), 19,569-19,585, doi:10.1029/1999JD900232

Koster R, Jouzel J, Suozzo R, Russell G, Broecker W, Rind D, Eagleson P (1986) Global sources of local precipitation as determined by the NASA GISS GCM. Geophys. Res. Lett. 13 (2), 121-124.

Koster RD, Dirmeyer PA, Guo ZC et al (2004) Regions of Strong Coupling Between Soil Moisture and Precipitation. Science, 305(5687), 1138-1140.

Koster RD, Mahanama SPP et al (2010). Contribution of land surface initialization to subseasonal forecast skill: First results from a multi-model experiment. Geophysical Research Letters, 37(L02402), 16. https://doi.org/10.1029/2009GL041677

Li RL囚 Bao HY, Li KC, Wang CH (2016) The memory and climate effects of global soil moisture. Journal of Glaciology and Geocryology, 38(6), 1470-1481.

Ni-Meister W, Walker JP, Houser PR (2005) Soil moisture initialization for climate prediction: Characterization of model and observation errors. Journal of Geophysical Research, 110(110), 379-391.

Pleim JE, Xiu A, (2003) Development of a Land Surface Model. Part II: Data Pleim, J. E., 2006: A simple, efficient solution of flux-profile relationships in the atmospheric surface layer, J. Appl. Meteor. and Clim., $45,341-347$.

Pleim (2007) A combined local and non-local closure model for the atmospheric boundary layer. Part2: Application and evaluation in a mesoscale meteorology model. JAMC, 46, 1396-1409.Assimilation. Journal of Applied Meteorology, 42(12),1811-1822.

Pleim JE, Gilliam R (2009) An Indirect Data Assimilation Scheme for Deep Soil Temperature in the PleimXiu Land Surface Model. Journal of Applied Meteorology \& Climatology, 48(7), 1362-1376.

Prodhomme C, Doblas-Reyes F, Bellprat O, Dutra E (2016) Impact of land-surface initialization on subseasonal to seasonal forecasts over Europe. Climate Dynamics, 47, 919-935.

https://doi.org/10.1007/s00382-015-2879-4.

Santanello JA, Peters-Lidard CD, Kumar SV, Alonge C, Tao WK (2009) A modeling and observational framework for diagnosing local land-atmosphere coupling on diurnal time scales. J. Hydrometeorol. 10 (3), 577-599.

Seneviratne SI et al. (2006a) Soil moisture memory in AGCM simulations: Analysis of Global LandAtmosphere Coupling Experiment (GLACE) data, J. Hydrometeorol, 7(5), 1090-1112. 
Seneviratne SI, Luthi D, Litschi M, Schar C (2006b) Land-atmosphere coupling and climate change in Europe, Nature, 443(7108), 205-209.

Seneviratne SI, Corti T, Davin EL et al (2010) Investigating soil moisture-climate interactions in a changing climate: A review. earth science reviews, 99(3-4),125-161.

Seneviratne SI et al (2013) Impact of soil moisture-climate feedbacks on CMIP5 projections: First results from the GLACE-CMIP5 experiment, Geophys. Res. Lett., 40, 5212-5217, doi:10.1002/grl.50956.

Shukla J, Mintz Y (1982) The influence of land-surface evaporation precipitation on earth's climate. Science, $215,1498-1501$.

Song YM, Guo WD, Zhang YC (2009) Numerical Study of Impacts of Soil Moisture on the Diurnal and Seasonal Cycles of Sensible/Latent Heat Fluxes over Semi-arid Region. Adv. Atmos. Sci., 26(2), 319-326.

Taylor CM, Parker DJ, Harris PP (2007) An observational case study of mesoscale atmospheric circulations induced by soil moisture. Geophys. Res. Lett. 34 (15) article nb: L15801.

Vitart F et al (2008) The new VAREPS-monthly forecasting system: A first step towards seamless prediction, Q. J. R. Meteorol. Soc., 134, 1789-1799, doi:10.1002/qj.322.

Walker J, Rowntree PR (1977) The effect of soil moisture on circulation and rainfall in a tropical model. Quart. J. Roy. Meteor. Soc., 103, 29-46.

Wang CH, Dong WJ, Wei ZG (2003) Study on Relationship between Freezing-Thawing Processes of the Qinghai-Tibet Plateau and the Atmospheric Circulation over East Asia. Chinese Journal of Geophysics., 46, 438-441, https://doi.org /10.1002/cjg2.3361.

Wang CH, Cui ZQ (2018) Improvement of Short-Term Climate Prediction with Indirect Soil Variables Assimilation in China. Journal of Climate, 31, 1399-1412.

Wang CH, Yang K, Zhang FM (2020) Impacts of Soil Freeze-Thaw Process and Snow Melting over Tibetan Plateau on Asian Summer Monsoon System: a Review and Perspective. Frontiers in Earth Science, 8, 133. https://doi.org/10.3389/feart.2020.00133

Wu WR, Marvin AG, Robert ED (2002) The Response of Soil Moisture to Long-Term Variability of Precipitation. Journal of Hydrometeorology, 3(5), 604-613.

Yang K, Wang CH, Bao HY (2016) Contribution of soil moisture variability to summer precipitation in the Northern Hemisphere, J. Geophys. Res. Atmos., 121, 12, 108-12, 124, doi:10.1002/2016JD025644.

Yang K, Wang CH (2019a) Water storage effect of soil freeze-thaw process and its impacts on soil hydrothermal regime variations. Agricultural and Forest Meteorology, 265, 280-294.

https://doi.org/10.1016/j.agrformet.2018.11.011 
Yang K, Wang CH (2019b) Seasonal persistence of soil moisture anomalies related to freeze-thaw over the Tibetan Plateau and prediction signal of summer precipitation in eastern China. Clim. Dyn., 53, 24112424.

Yeh TC, Wetherald RT, Manable S (1984) The Effect of Soil Moisture on the Short-Term Climate and Hydrology Change-A Numerical Experiment. Monthly Weather Review, 112, 474-490.

Zhang T, R. G. Barry, K. Knowles, F. Ling, and R. Armstrong, 2003: In: Phillips, Springman, Arenson (Eds.), Distribution of Seasonally and Perennially Frozen Ground in the Northern Hemisphere. Permafrost, pp. 1289-1294.

\section{Figures}




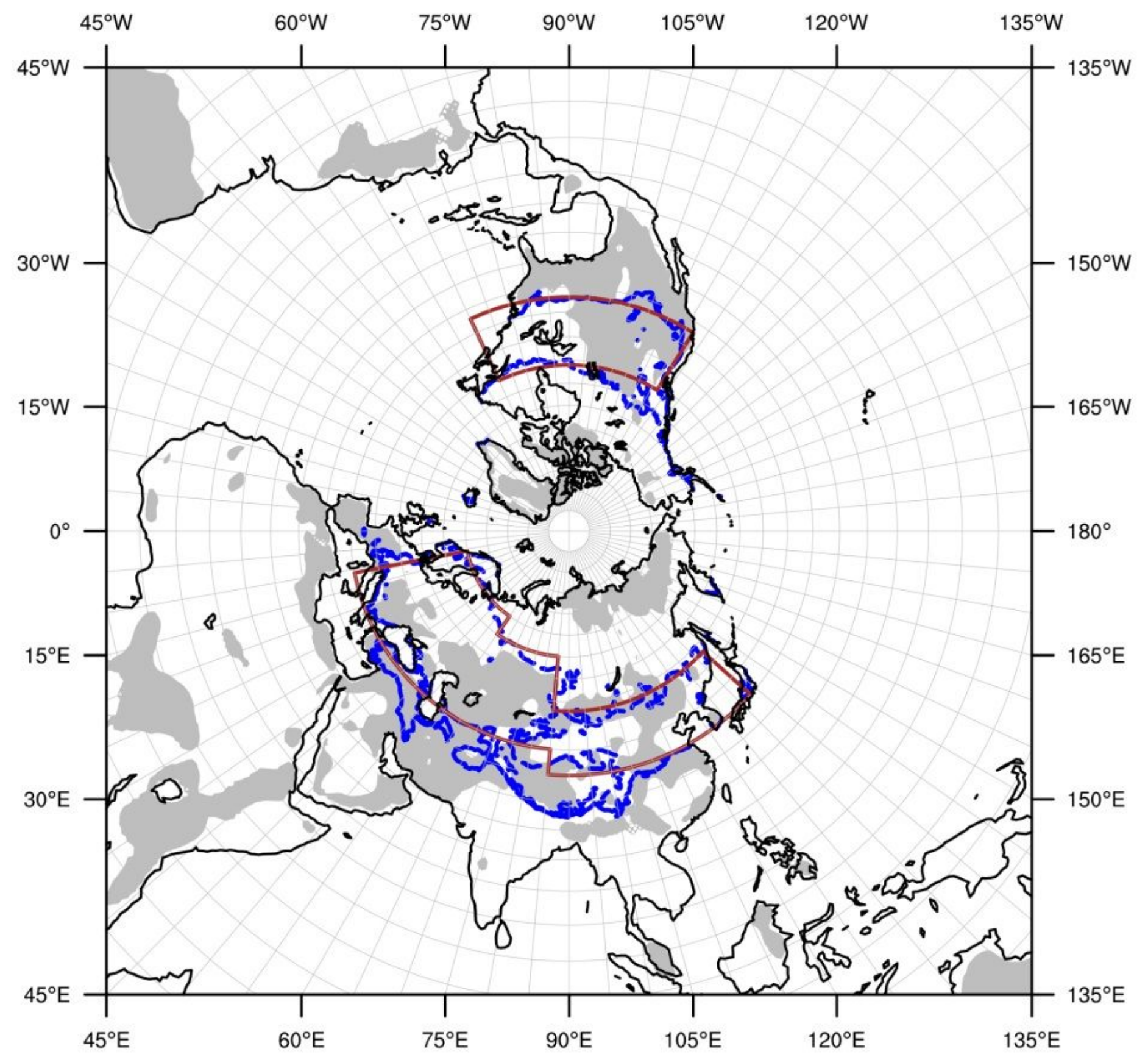

Figure 1

Simulation domain in this study. Regions surrounded by blue lines indicate the seasonal frozen-thawing zone (SFTZ, dashed and solid isotherms lines represent January $0{ }^{\circ} \mathrm{C}$ and annual $0{ }^{\circ} \mathrm{C}$, separately, on climatological mean). Brown lines denote the region where soil moisture (SM) is assimilated. Gray shaded colors indicate regions where the standard deviation of spring (March-May average) SM at 1-m depth are larger than $0.025 \mathrm{~m} 3 \mathrm{~m}-3$ for the period 1979-2019 from ERA5. Note: The designations employed and the presentation of the material on this map do not imply the expression of any opinion whatsoever on the part of Research Square concerning the legal status of any country, territory, city or 
area or of its authorities, or concerning the delimitation of its frontiers or boundaries. This map has been provided by the authors.
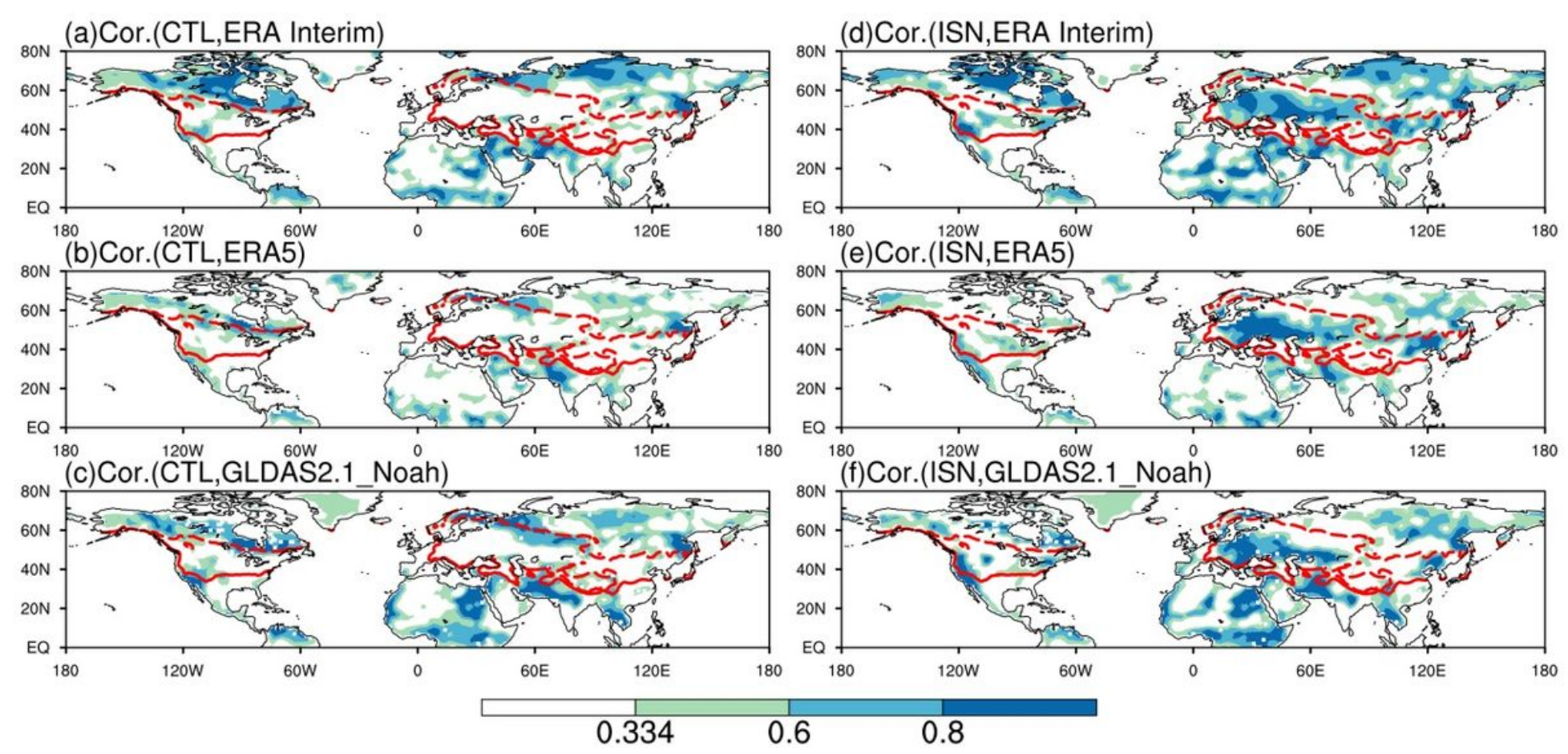

$0.6 \quad 0.8$

Figure 2

Correlation coefficients of spring SM (unit: $\mathrm{m} 3 \mathrm{~m}-3$ ) at 1-m depth between the CTL experiment and (a) ERA-Interim, (b) ERA5, (c) GLDAS2.1 Noah. (d-f) Same as Figures 2a-c but for the ISN experiment. The shaded areas (correlation coefficients $>0.334$ ) proved statistically significant at the $99.9 \%$ confidence level. Regions surrounded by red lines are the SFTZ. Note: The designations employed and the presentation of the material on this map do not imply the expression of any opinion whatsoever on the part of Research Square concerning the legal status of any country, territory, city or area or of its authorities, or concerning the delimitation of its frontiers or boundaries. This map has been provided by the authors. 
(a)30-60N,North America

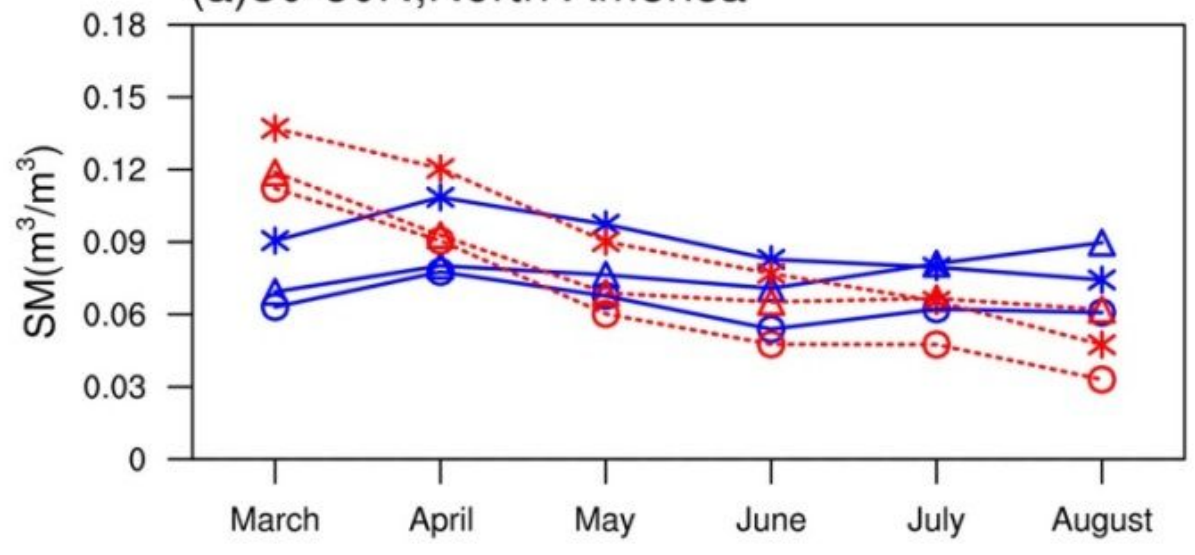

(b)30-60N,Eurasia

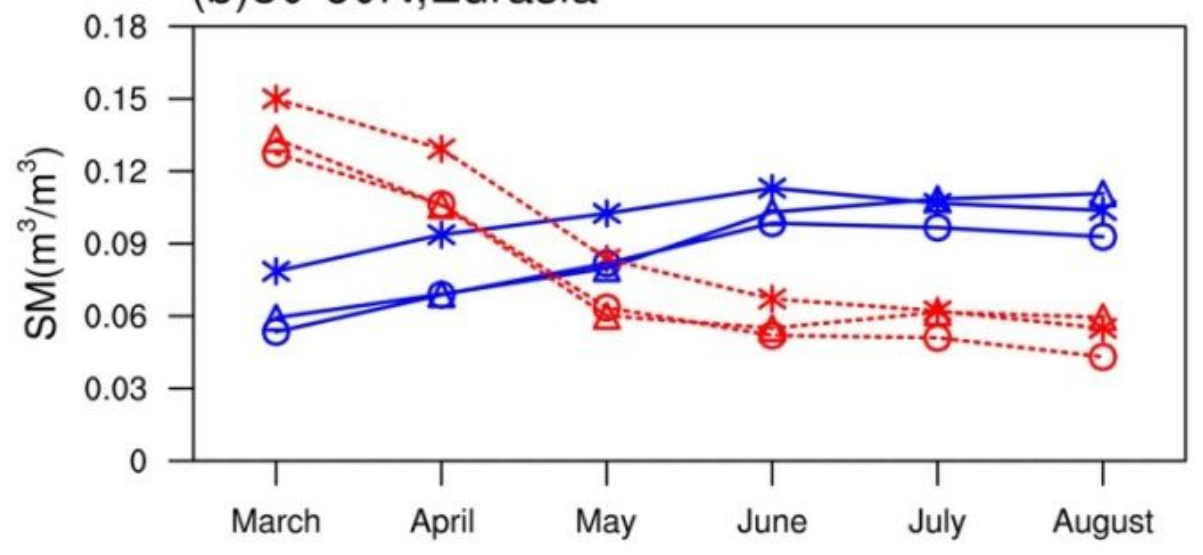

(c)North Hemisphere

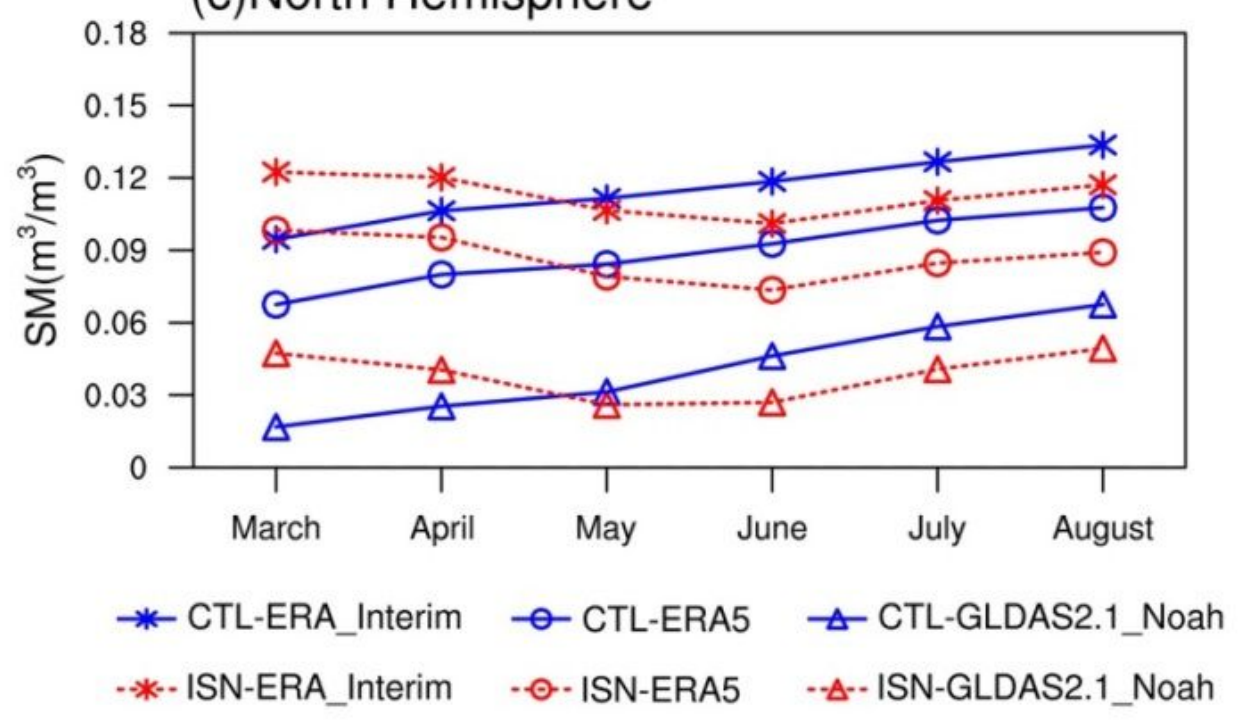

\section{Figure 3}

The difference of area-averaged SM between experiments (CTL and ISN) and reanalysis data (ERAInterim, ERA5, and GLDAS2.1 Noah) over (a) North America at $30-60^{\circ} \mathrm{N}$, (b) Eurasia at $30-60^{\circ} \mathrm{N}$, and (c) Northern Hemisphere. 
(a)Dif.(CTL,ERA Interim)
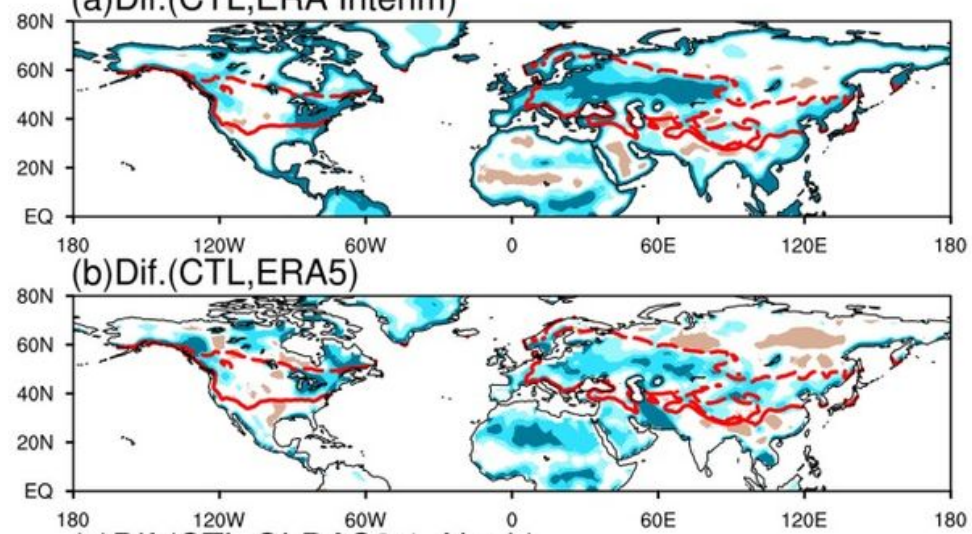

(c)Dif.(CTL,GLDAS2.1_Noah)
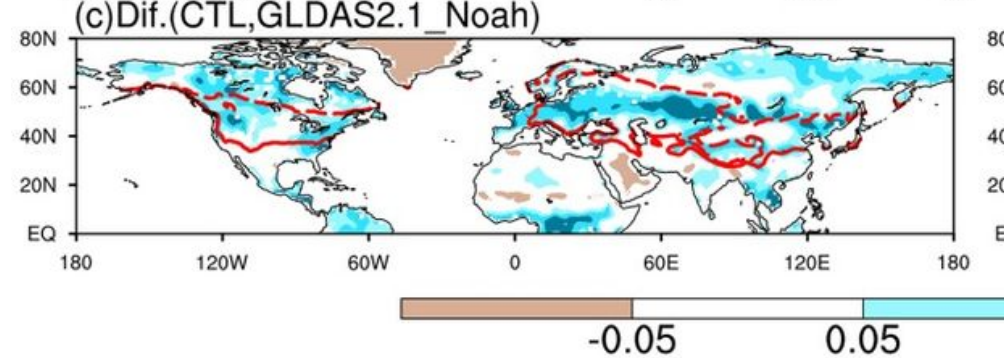

(d)Dif.(ISN,ERA Interim)
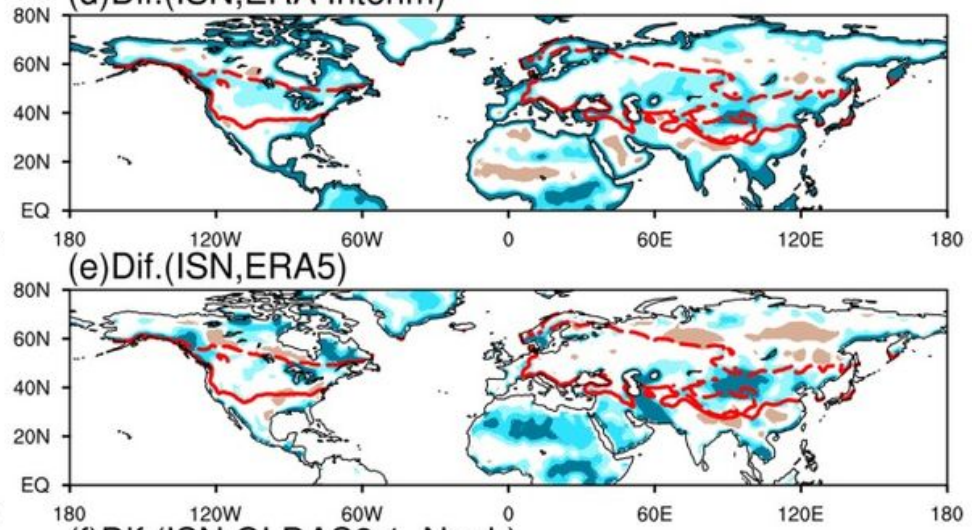

${ }^{180}$ (f)Dif.(ISN,GLDAS2.1_Noah)

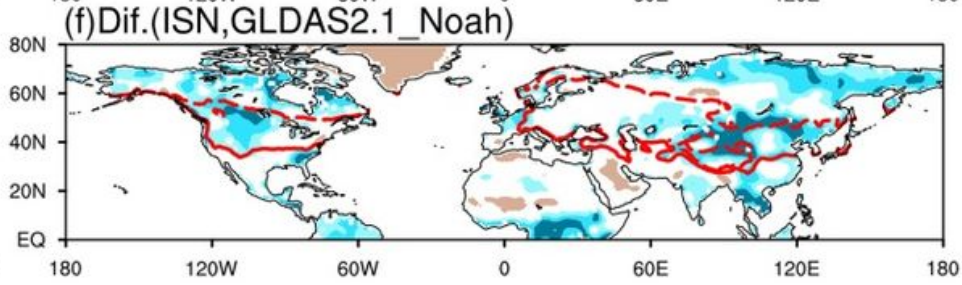

Figure 4

The difference of SM (unit: m3 m-3) at 1-m depth in May between the CTL experiment and (a) ERAInterim, (b) ERA5, and (c) GLDAS2.1 Noah. (d-f) Same as Figures 4a-c but for the ISN experiment. Regions surrounded by red lines are the SFTZ. Note: The designations employed and the presentation of the material on this map do not imply the expression of any opinion whatsoever on the part of Research Square concerning the legal status of any country, territory, city or area or of its authorities, or concerning the delimitation of its frontiers or boundaries. This map has been provided by the authors. 
(a) $0-30 \mathrm{~N}$

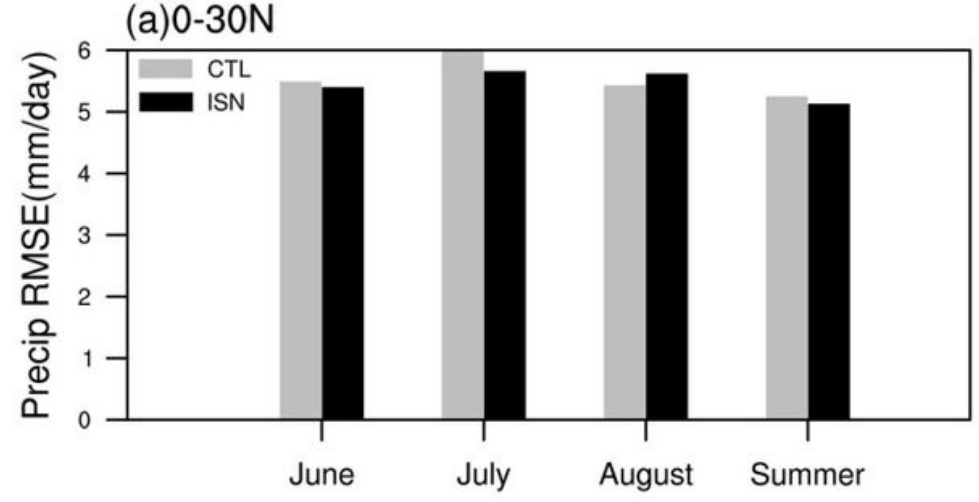

(b) $30-60 \mathrm{~N}$

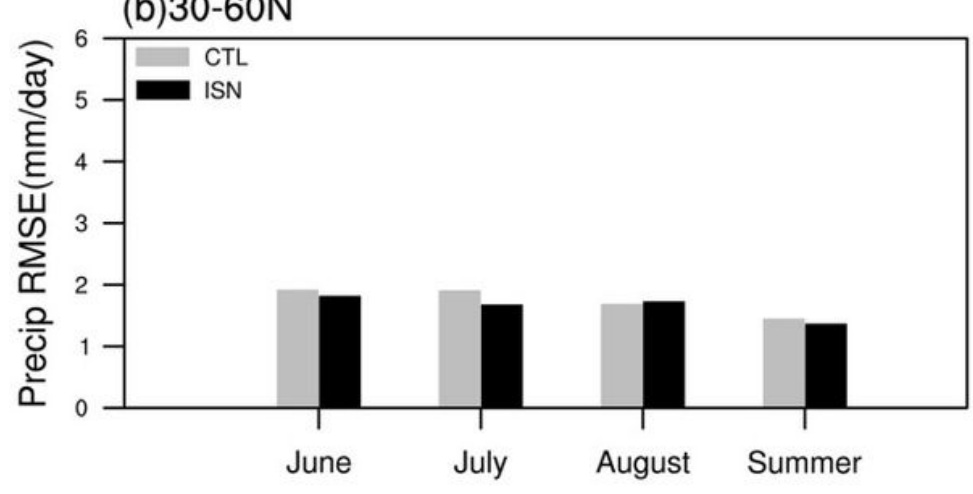

(c)60-90N

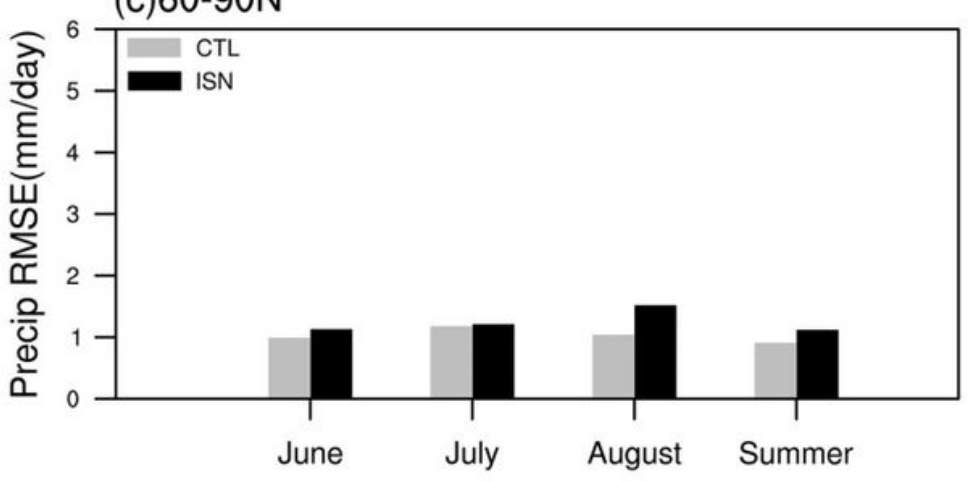

(d) $0-90 \mathrm{~N}$

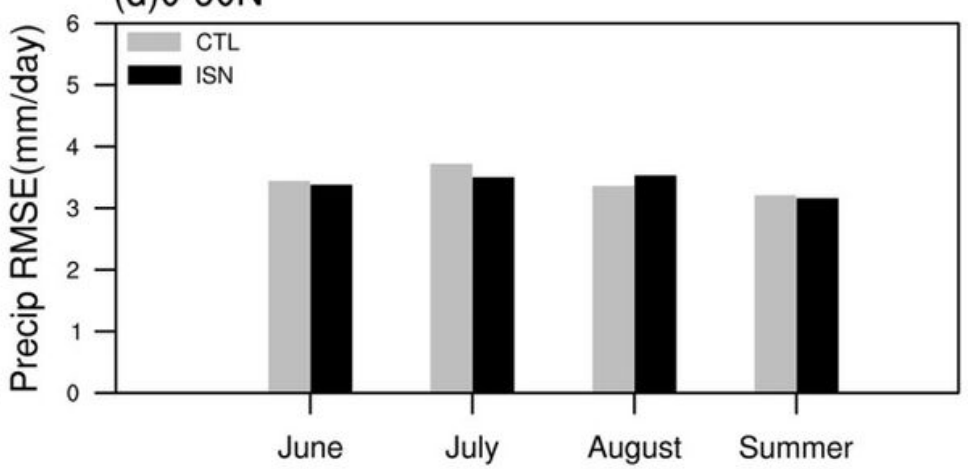

Figure 5

Root-mean-square error (RMSE) of land precipitation (unit: $\mathrm{mm}$ day-1) in June, July, August, and the general summer at (a) $0-30^{\circ} \mathrm{N}$, (b) $30-60^{\circ} \mathrm{N}$, (c) $60-90^{\circ} \mathrm{N}$, and (d) $0-90^{\circ} \mathrm{N}$ in comparison with the precipitation from CPC. The gray (black) bars indicate the RMSE of the CTL (ISN) experiment. 
(a)June,Dif.(CTL-CPC)/Dif.(ISN-CPC)

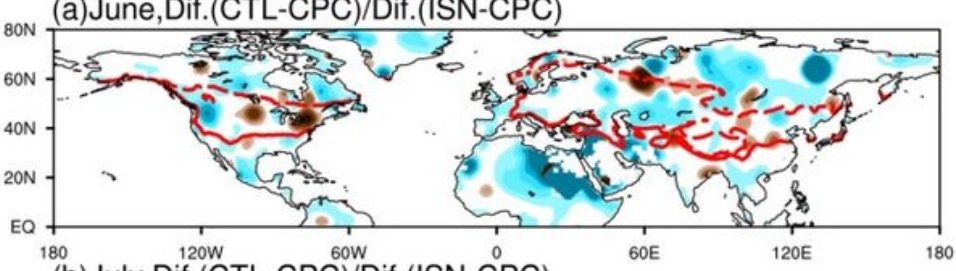

(b)July,Dif.(CTL-CPC)/Dif.(ISN-CPC)

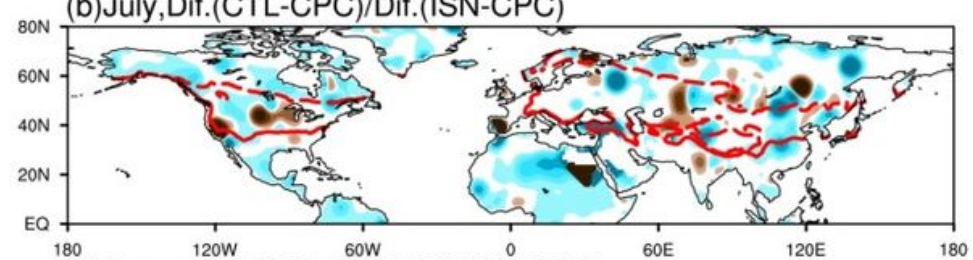

${ }^{180}$ (C)August,Dif.(CTL-CPC)/Dif.(ISN-CPC)
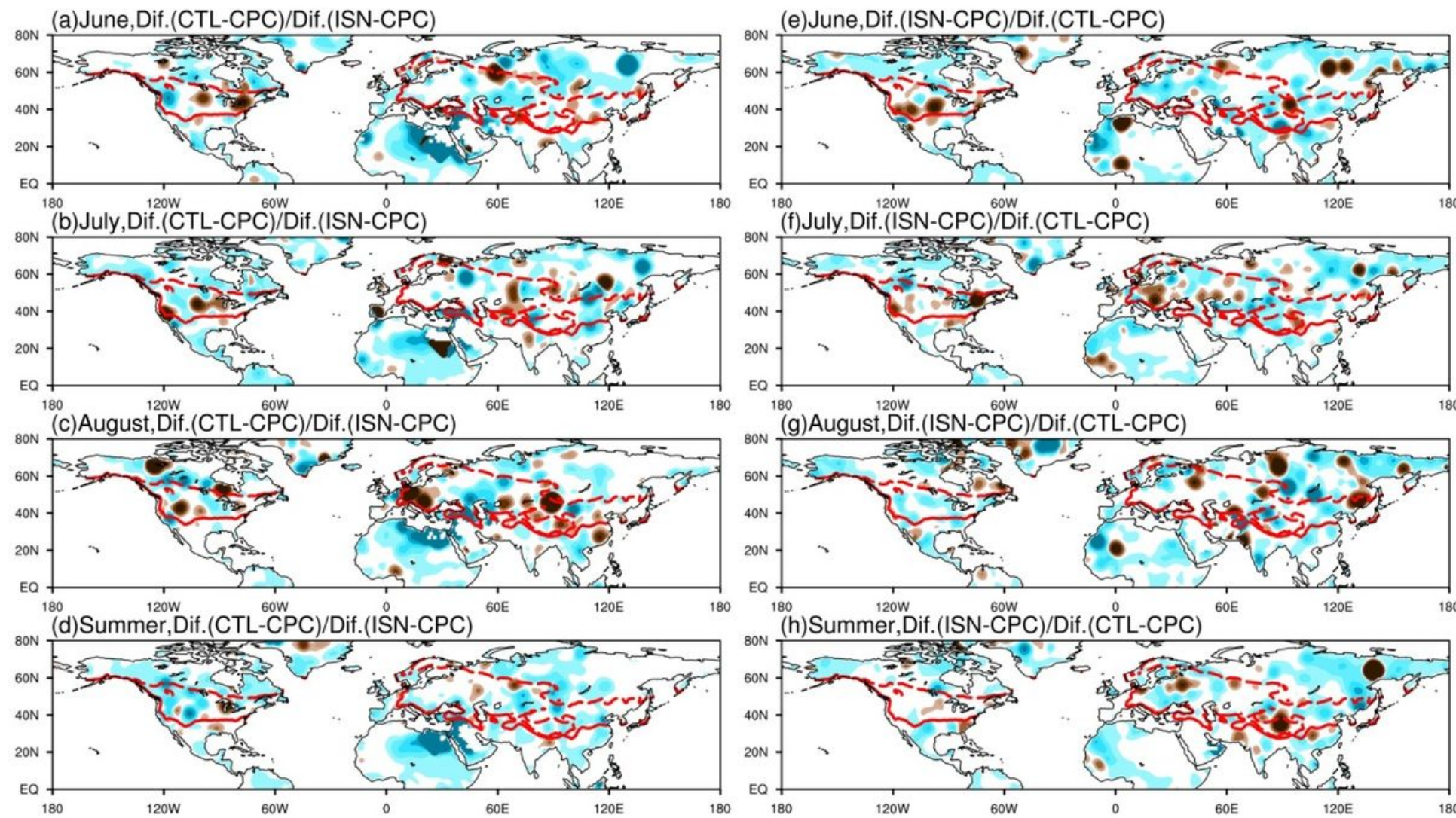

${ }^{180}$ (f)July,Dif.(ISN-CPC)/Dif.(CTL-CPC)

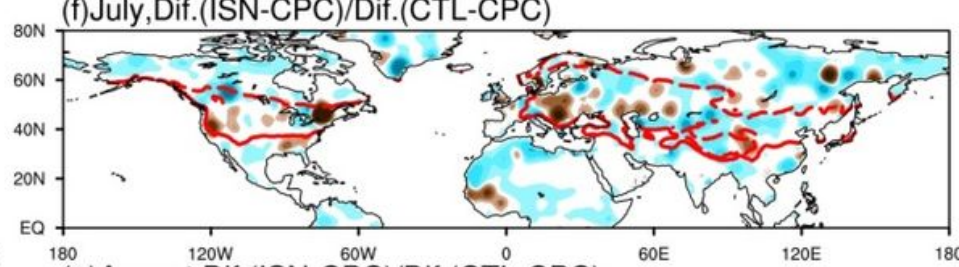

${ }^{180}$ (g)August,Dif.(ISN-CPC)/Dif.(CTL-CPC)

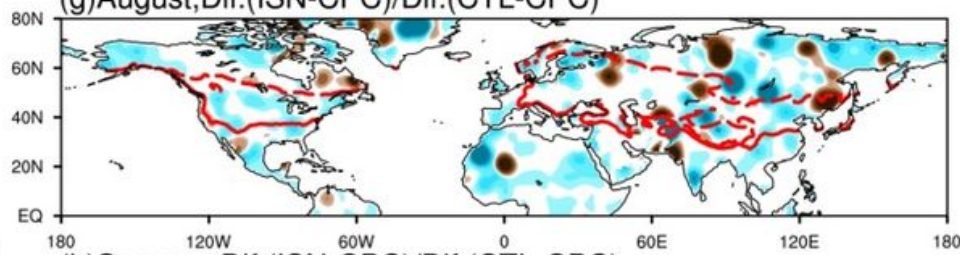

(h) Summer,Dif.(ISN-CPC)/Dif.(CTL-CPC)

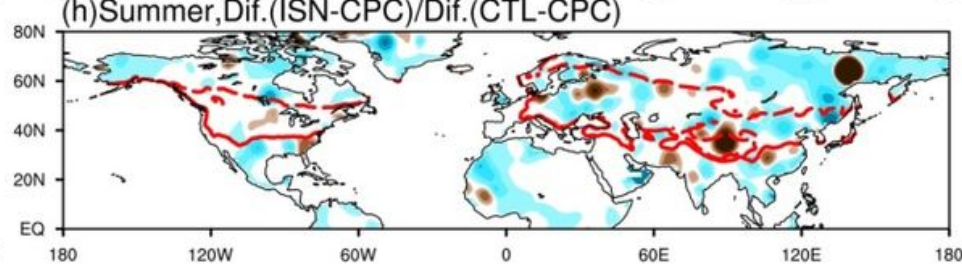

16

Figure 6

Left panel: the ratio between the precipitation biases of the CTL experiment (CTL minus CPC) and the ISN experiment (ISN minus CPC) in (a) June, (b) July, (c) August, and (d) summer. Right panel: the multiplicative inverse of ratio in the left panel in (e) June, (f) July, (g) August, and (h) summer. Absolute values of a ratio greater than 1 in the left (right) panel indicate that the ISN (CTL) experiment has better performance of precipitation simulation than has the CTL (ISN) experiment. Regions surrounded by red lines are the SFTZ. Note: The designations employed and the presentation of the material on this map do not imply the expression of any opinion whatsoever on the part of Research Square concerning the legal status of any country, territory, city or area or of its authorities, or concerning the delimitation of its frontiers or boundaries. This map has been provided by the authors. 
(a) LH

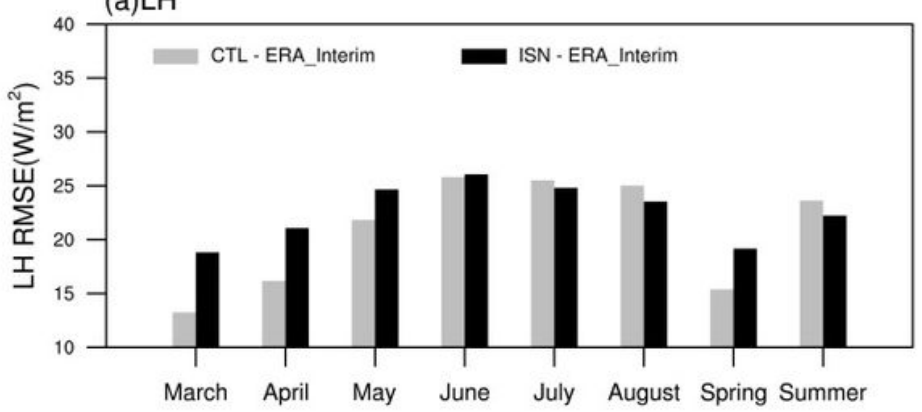

(b) LH

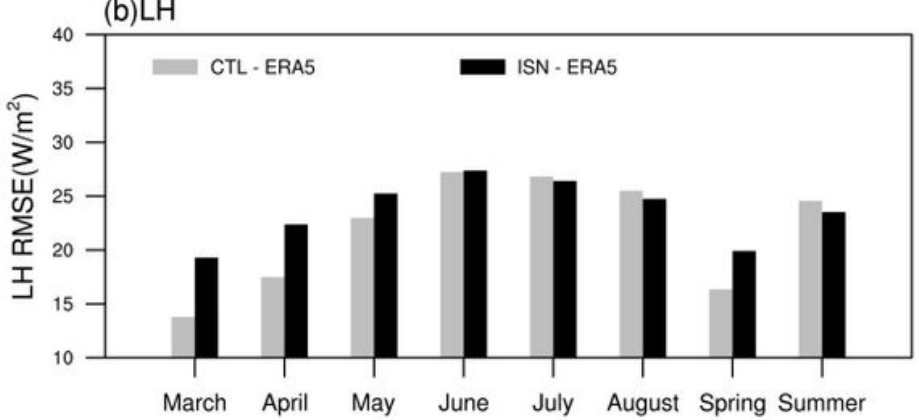

(c) $\mathrm{LH}$

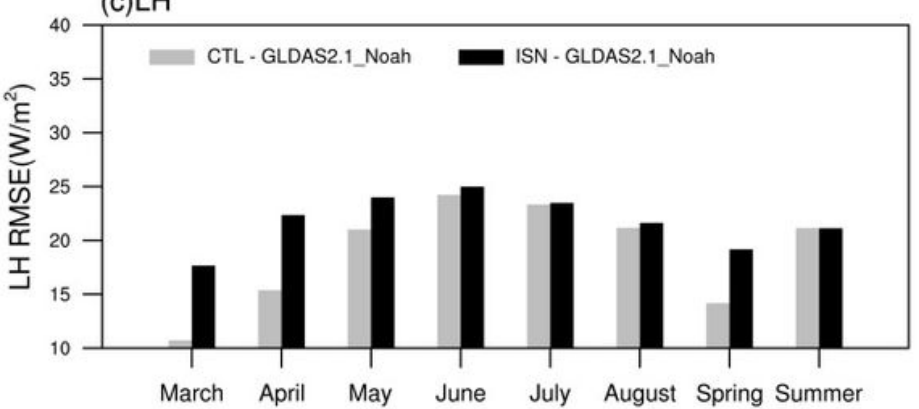

(d) $\mathrm{SH}$

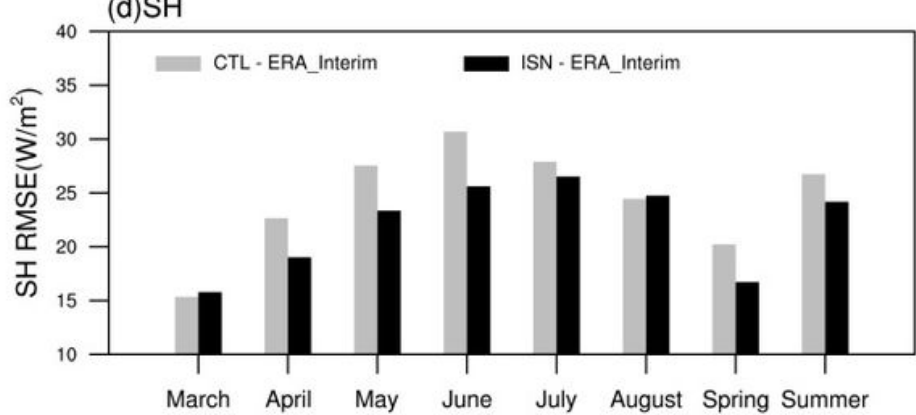

(e) $\mathrm{SH}$
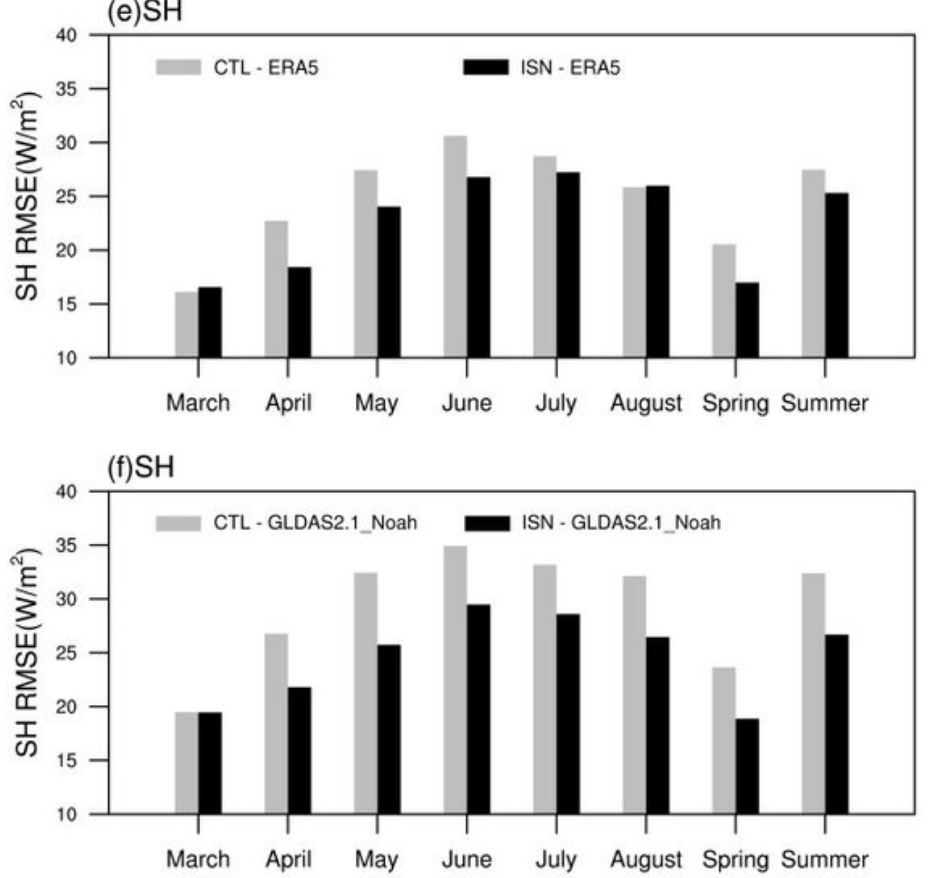

Figure 7

RMSE of land surface latent heat flux (LH, unit: W m-2) compared with (a) ERA-Interim, (b) ERA5, and (c) GLDAS2.1 Noah at $30-60^{\circ} \mathrm{N}$ from March to August and in the spring and summer. (d-f) Same as Figures $7 \mathrm{a}-\mathrm{c}$ but for sensible heat flux (SH, unit: $\mathrm{W} \mathrm{m-2}$ ). The gray (black) bars indicate the RMSE of the CTL (ISN) experiment. 
(a)Dif.(CTL,ERA_interim)
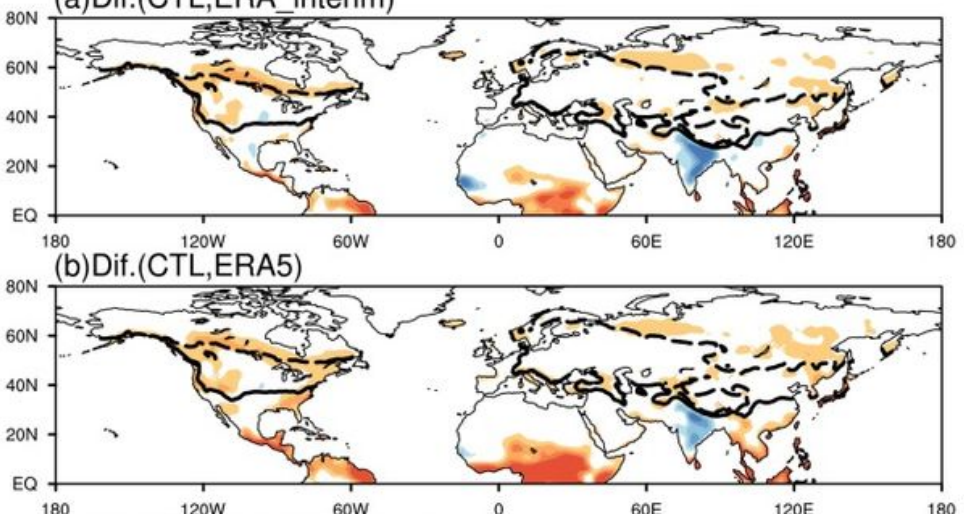

${ }^{180}$ (c)Dif.(CTL,GLDAS2.1 Noah)
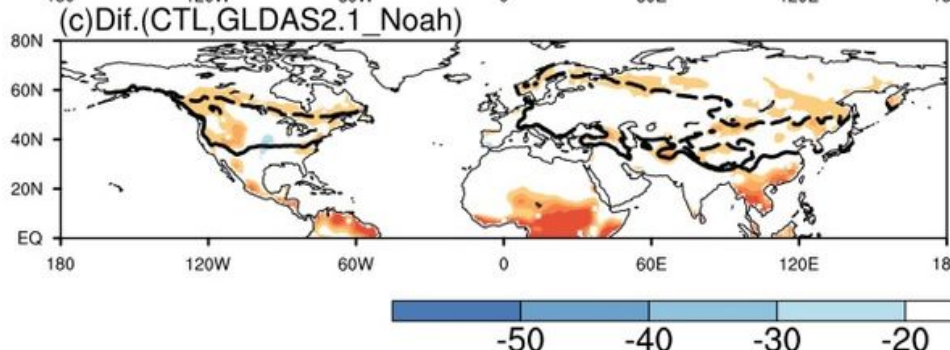

$180 \quad 180$

(d)Dif.(ISN,ERA interim)

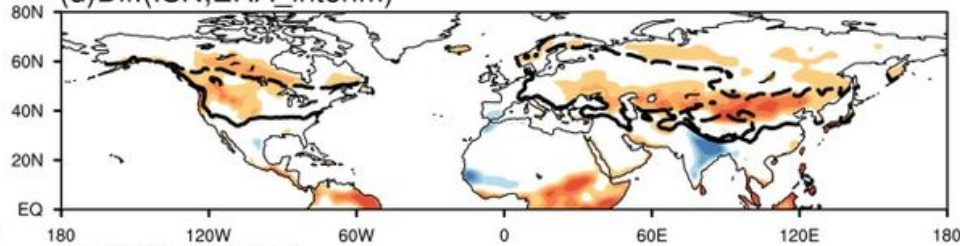

${ }^{180}$ (e)Dif.(ISN,ERA5)

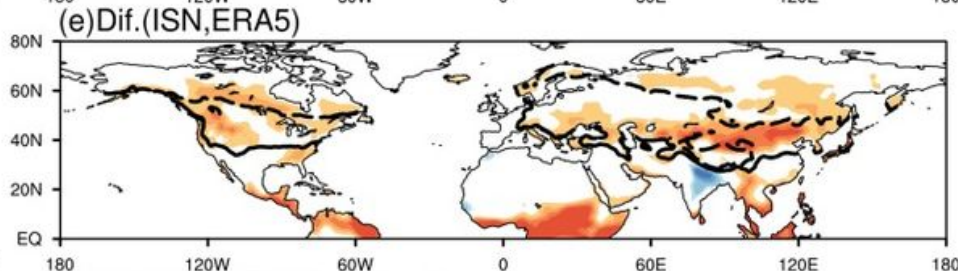

${ }^{180}$ (f)Dif.(ISN,GLDAS2.1 ${ }^{120 W}$ Noah)

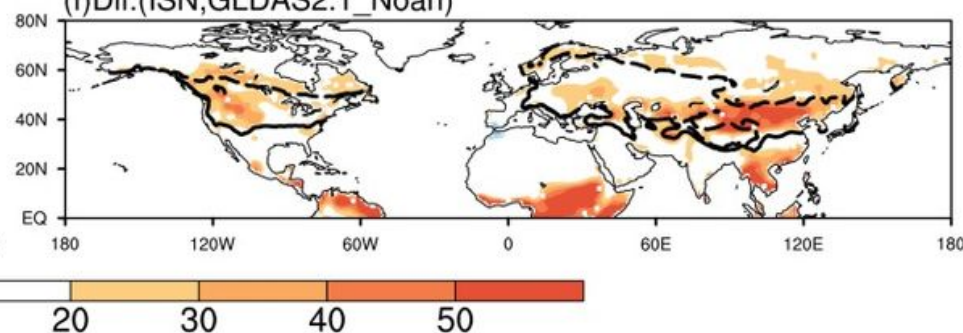

Figure 8

Differences in spring LH (unit: W m-2) between the CTL experiment and (a) ERA-Interim, (b) ERA5, and (c) GLDAS2.1 Noah. (d-f) Same as Figures 8a-c but for the ISN experiment. Regions surrounded by black lines are the SFTZ. Note: The designations employed and the presentation of the material on this map do not imply the expression of any opinion whatsoever on the part of Research Square concerning the legal status of any country, territory, city or area or of its authorities, or concerning the delimitation of its frontiers or boundaries. This map has been provided by the authors.

(a)Dif.(CTL,ERA_interim)

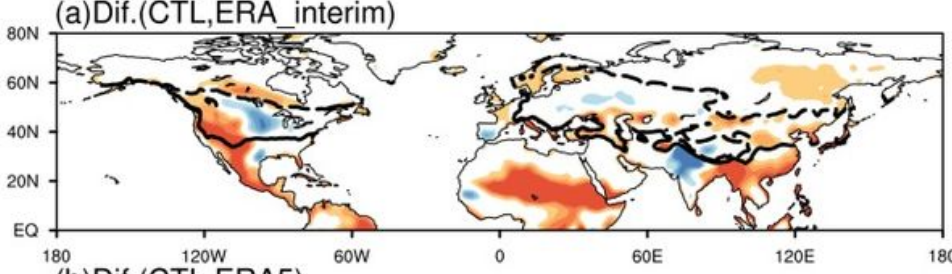

(b)Dif.(CTL,ERA5)
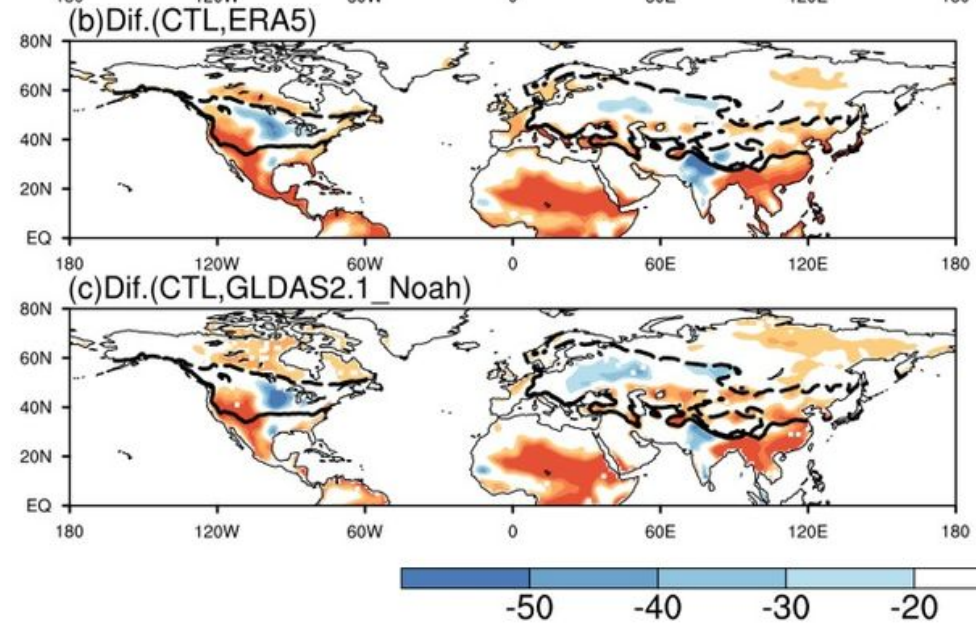

180

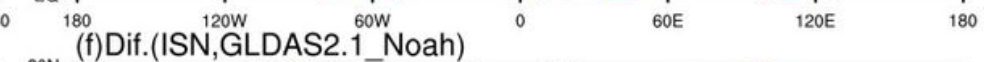

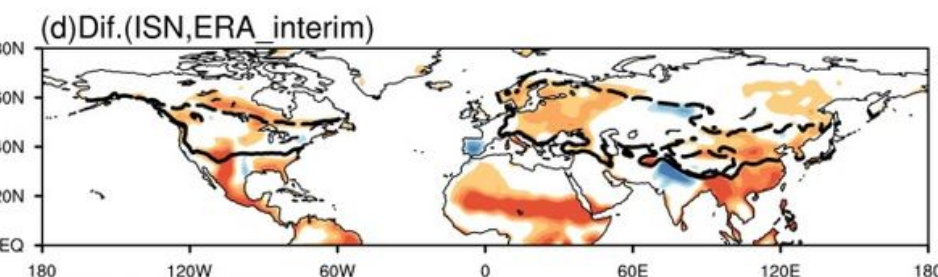

(e)Dif.(ISN,ERA5)
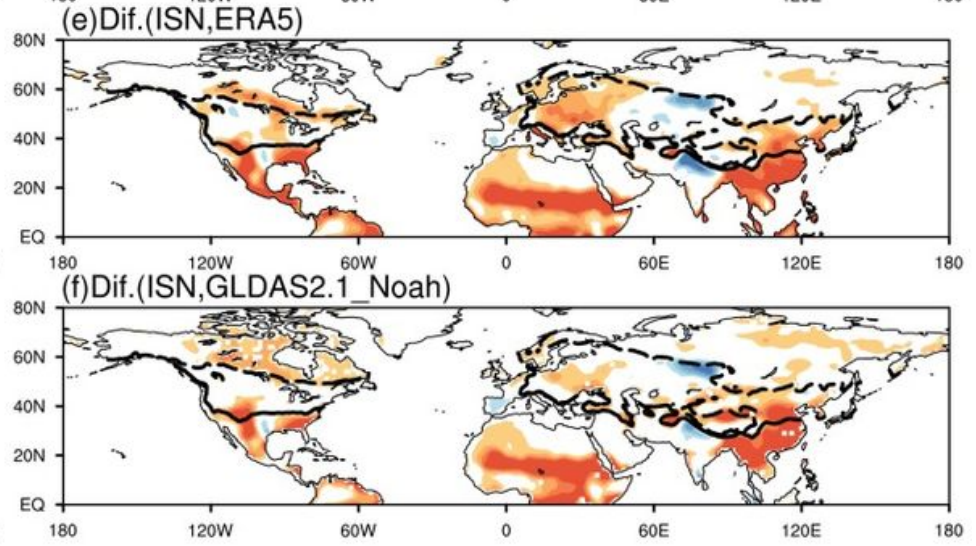


\section{Figure 9}

Differences in summer LH (unit: $\mathrm{W} \mathrm{m-2}$ ) between the CTL experiment and (a) ERA-Interim, (b) ERA5, and (c) GLDAS2.1 Noah. (d-f) Same as Figures $9 a-c$ but for the ISN experiment. Regions surrounded by black lines are the SFTZ. Note: The designations employed and the presentation of the material on this map do not imply the expression of any opinion whatsoever on the part of Research Square concerning the legal status of any country, territory, city or area or of its authorities, or concerning the delimitation of its frontiers or boundaries. This map has been provided by the authors.
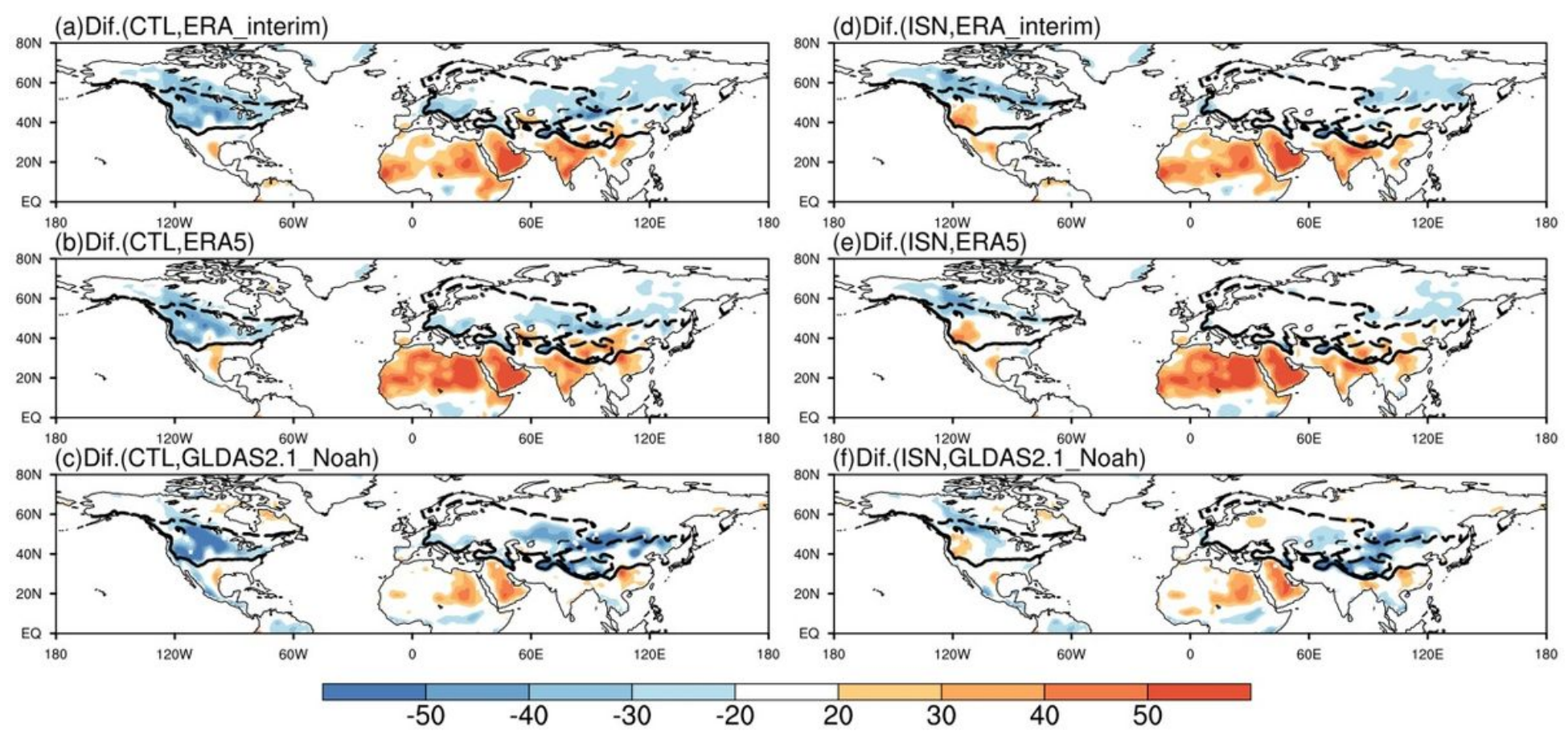

Figure 10

Differences in spring SH (unit: $\mathrm{W} \mathrm{m}$-2) between the CTL experiment and (a) ERA-Interim, (b) ERA5, and (c) GLDAS2.1 Noah. (d-f) Same as Figures $10 a-c$ but for the ISN experiment. Regions surrounded by black lines are the SFTZ. Note: The designations employed and the presentation of the material on this map do not imply the expression of any opinion whatsoever on the part of Research Square concerning the legal status of any country, territory, city or area or of its authorities, or concerning the delimitation of its frontiers or boundaries. This map has been provided by the authors. 
(a)Dif.(CTL,ERA interim)

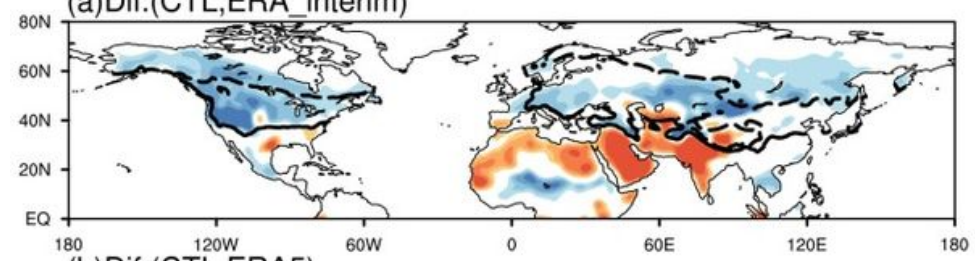

(b)Dif.(CTL,ERA5)

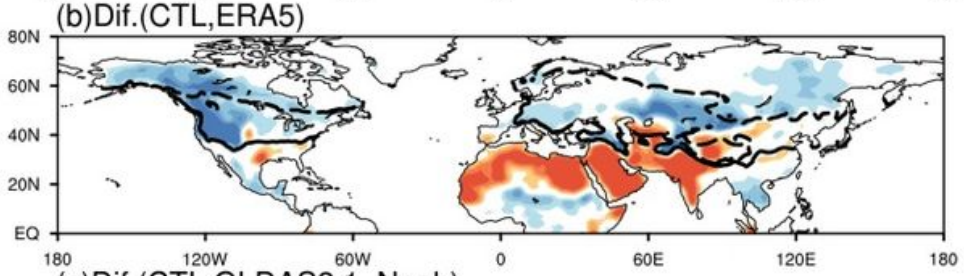

${ }^{180}$ (c)Dif.(CTL,GLDAS2.1_Noah)

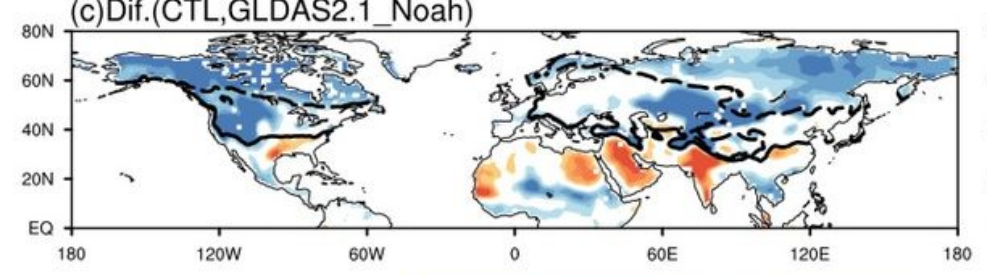

(d)Dif.(ISN,ERA interim)

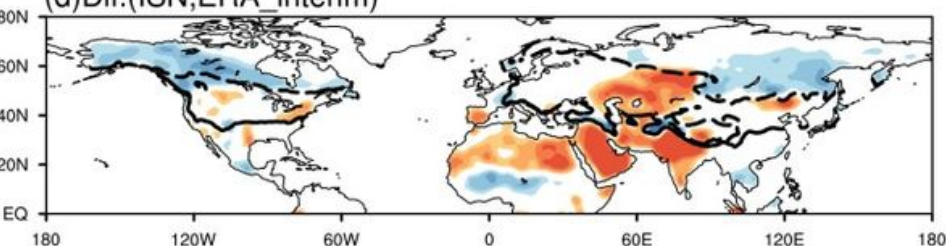

(e)Dif.(ISN,ERA5)

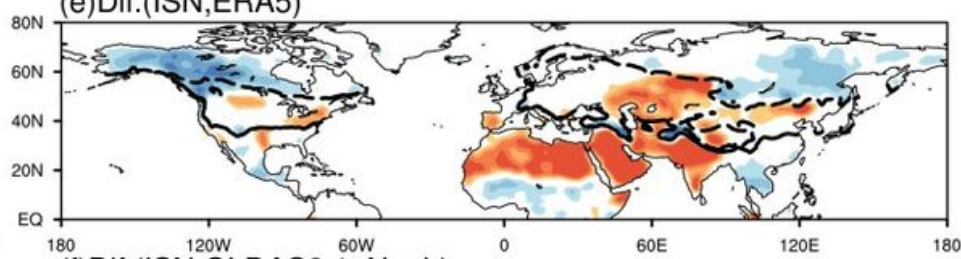

(f)Dif.(ISN,GLDAS2.1_Noah)

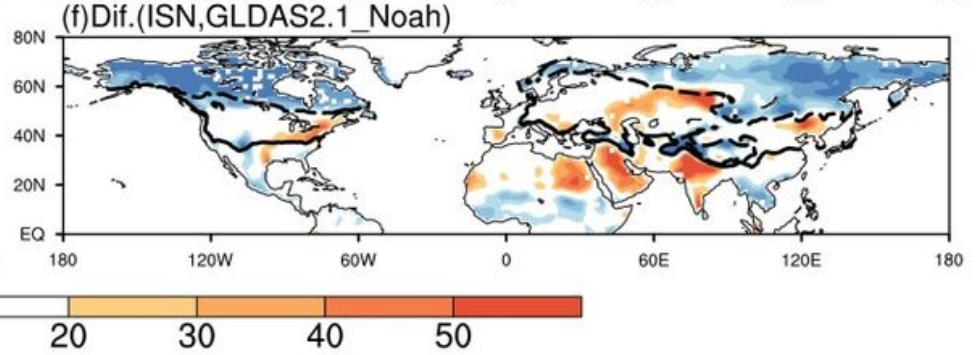

Figure 11

Differences in summer SH (unit: $\mathrm{W} \mathrm{m}$-2) between the CTL experiment and (a) ERA-Interim, (b) ERA5, and (c) GLDAS2.1 Noah. (d-f) Same as Figures 11a-c but for the ISN experiment. Regions surrounded by black lines are the SFTZ. Note: The designations employed and the presentation of the material on this map do not imply the expression of any opinion whatsoever on the part of Research Square concerning the legal status of any country, territory, city or area or of its authorities, or concerning the delimitation of its frontiers or boundaries. This map has been provided by the authors.
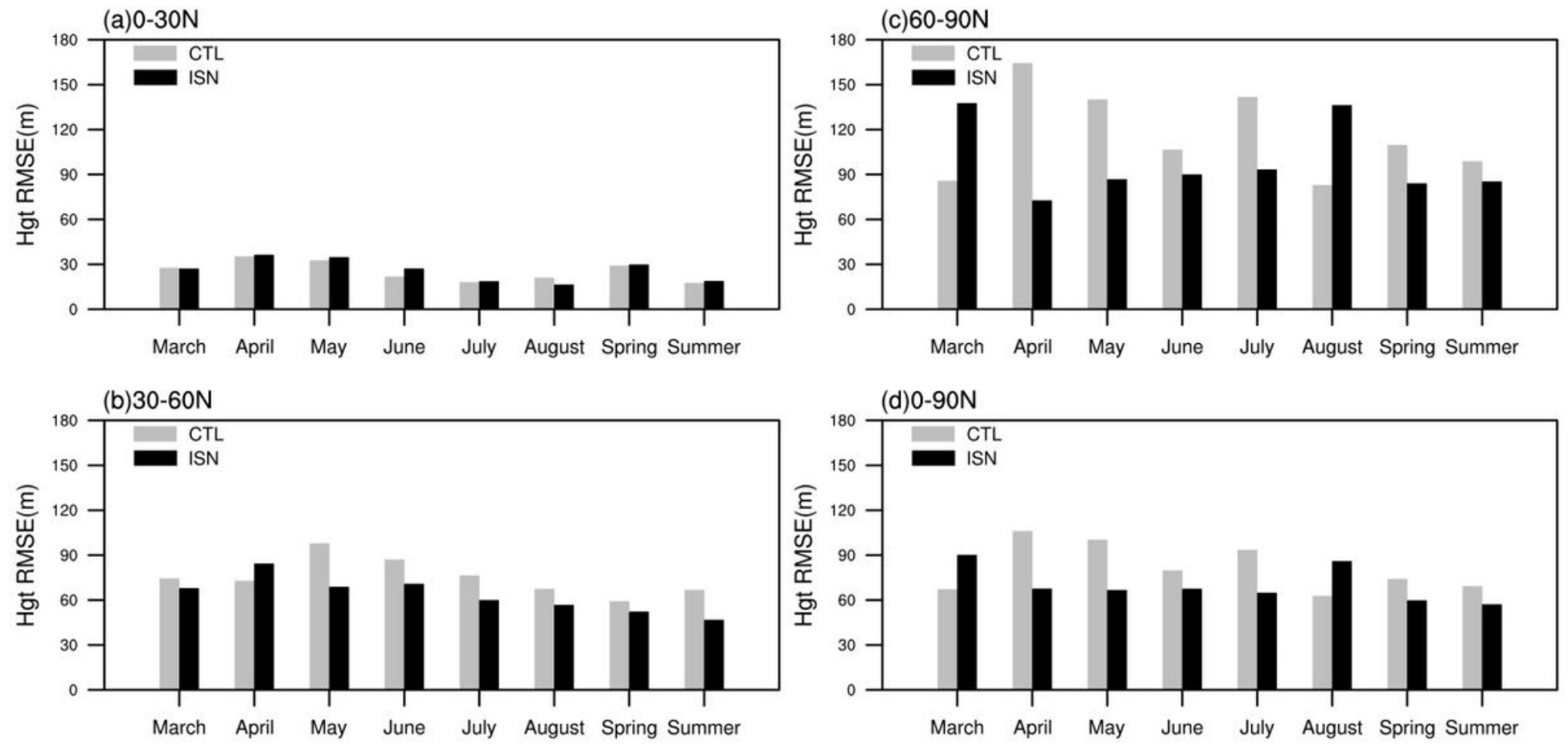
Figure 12

RMSE of the $500-\mathrm{hPa}$ geopotential height (unit: $\mathrm{m}$ ) at (a) $0-30^{\circ} \mathrm{N}$, (b) $30-60^{\circ} \mathrm{N}$, (c) $60-90^{\circ} \mathrm{N}$, and (d) $0-$ $90^{\circ} \mathrm{N}$ from March to August and in the spring and summer compared with ERA5. The gray (black) bars indicate the RMSE of the CTL (ISN) experiment.

(a)June,Dif.(CTL-ERA5)

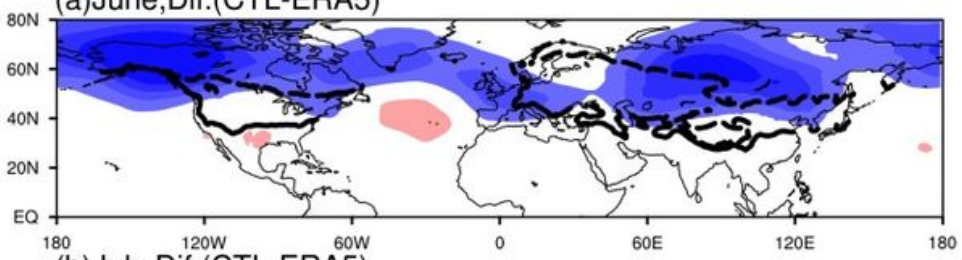

(b)July,Dif.(CTL-ERA5)

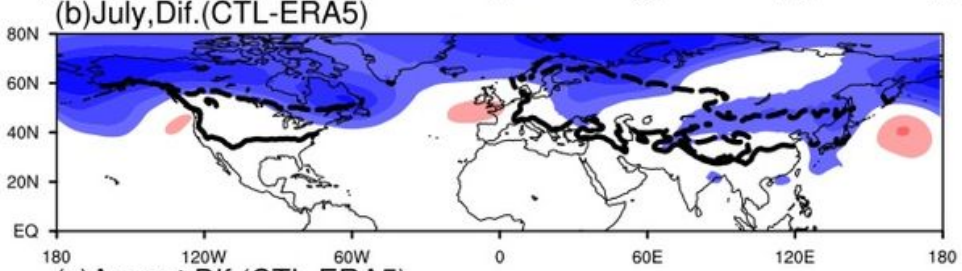

(c)August,Dif.(CTL-ERA5)

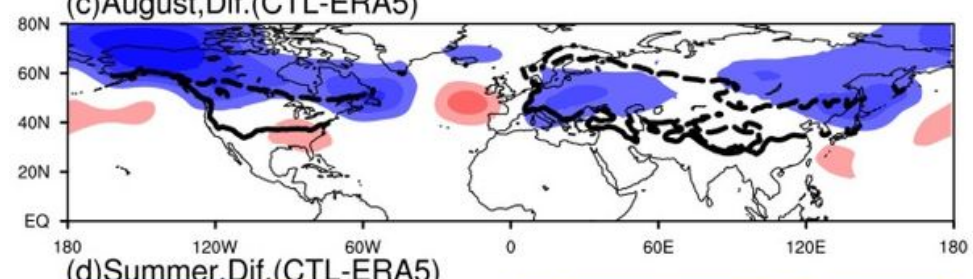

${ }_{80 \mathrm{~N}}$ (d)Summer,Dif.(CTL-ERA5)

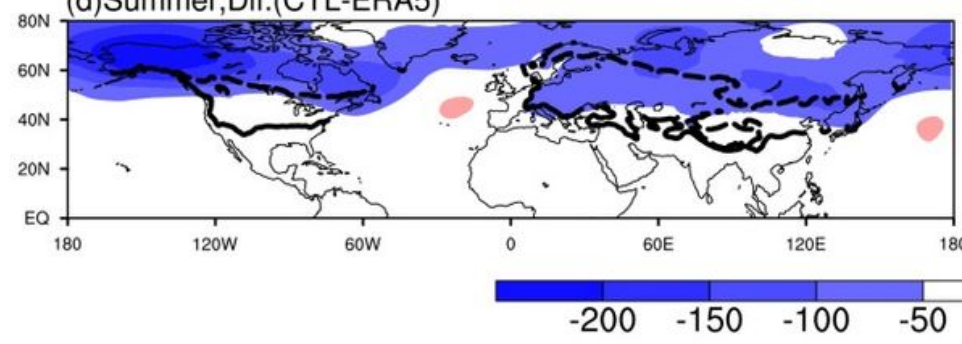

(e)June,Dif.(ISN-ERA5)

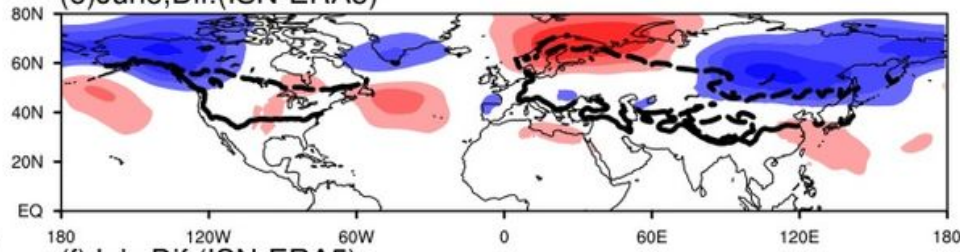

(f)July,Dif.(ISN-ERA5)

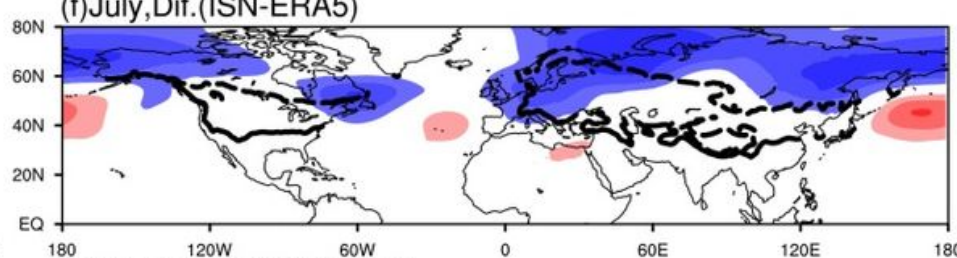

(g)August,Dif.(ISN-ERA5)

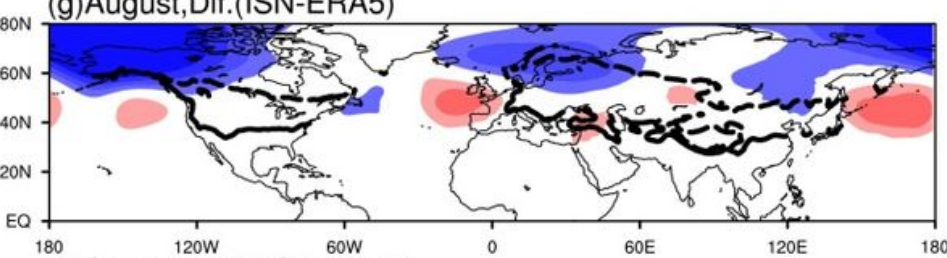

(h)Summer,Dif.(ISN-ERA5)

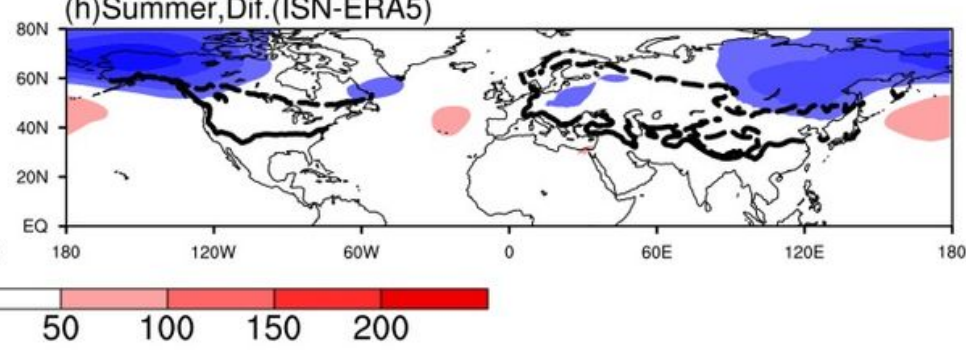

Figure 13

Differences in the 500-hPa geopotential height (unit: $\mathrm{m}$ ) between the CTL experiment and ERA5 in (a) June, (b) July, (c) August, and (d) summer. (d-f) Same as Figures 13a-c but for the ISN experiment. Regions surrounded by black lines are the SFTZ. Note: The designations employed and the presentation of the material on this map do not imply the expression of any opinion whatsoever on the part of Research Square concerning the legal status of any country, territory, city or area or of its authorities, or concerning the delimitation of its frontiers or boundaries. This map has been provided by the authors. 
(a)Dif.(CTL,ERA5)

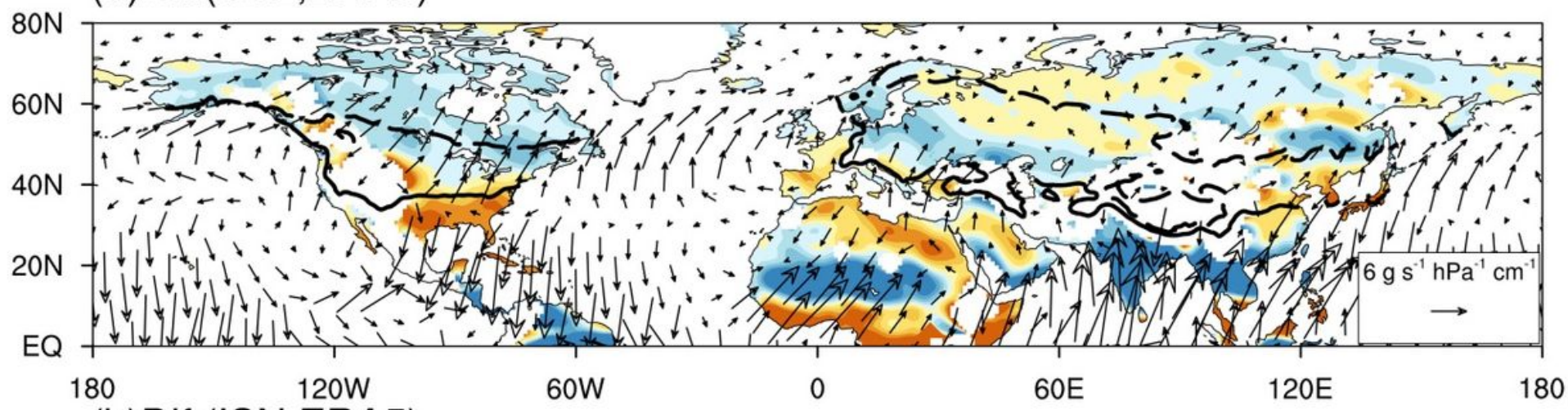

(b)Dif.(ISN,ERA5)

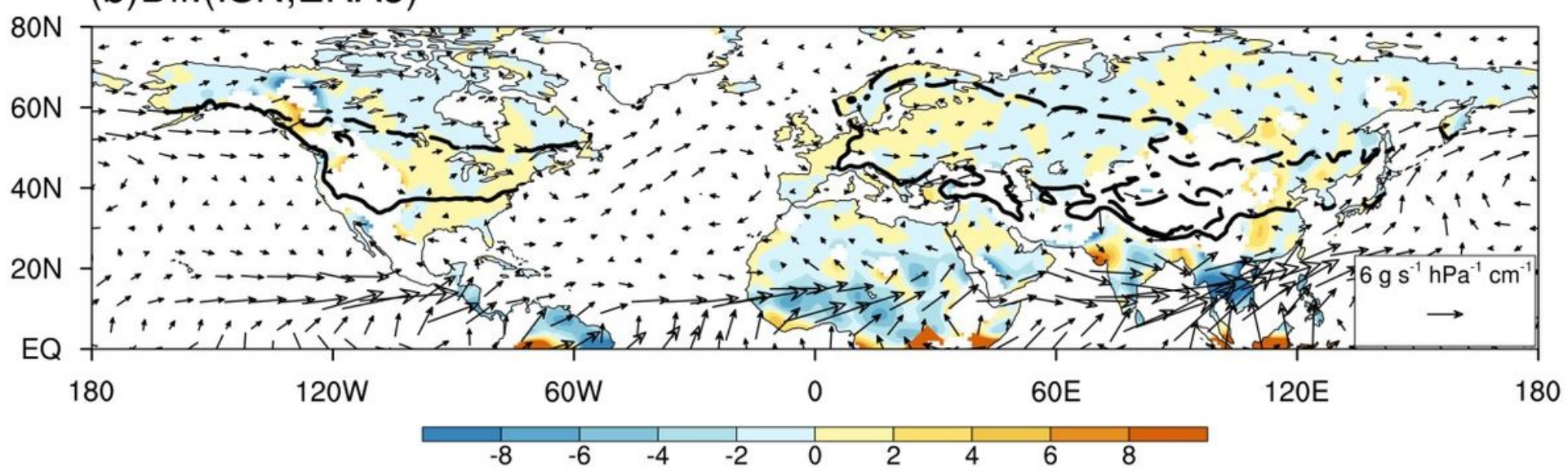

Figure 14

The difference in water vapor flux (vector, g s $-1 \mathrm{hPa}-1 \mathrm{~cm}-1$ ) and its divergence (shading, $10-6 \mathrm{~g} \mathrm{~s}-1$ $\mathrm{hPa}-1 \mathrm{~cm}-2$ ) at $850 \mathrm{hPa}$ in the summer between (a) the CTL experiment and ERA5, and (b) the ISN experiment and ERA5. Regions surrounded by black lines are the SFTZ. Note: The designations employed and the presentation of the material on this map do not imply the expression of any opinion whatsoever on the part of Research Square concerning the legal status of any country, territory, city or area or of its authorities, or concerning the delimitation of its frontiers or boundaries. This map has been provided by the authors. 